TFBP-TR-289

for U.S. Nuclear Regulatory Commission

\title{
REACTIVITY INITIATED ACCIDENT TEST SERIES \\ RIA SCOPING TEST QUICK LOOK REPORT
}

\author{
Z.R. MARTINSON \\ R.S. SEMKEN \\ T. INABE \\ R.H. SMITH \\ T.F. COOK \\ A.D. APPELHANS
}

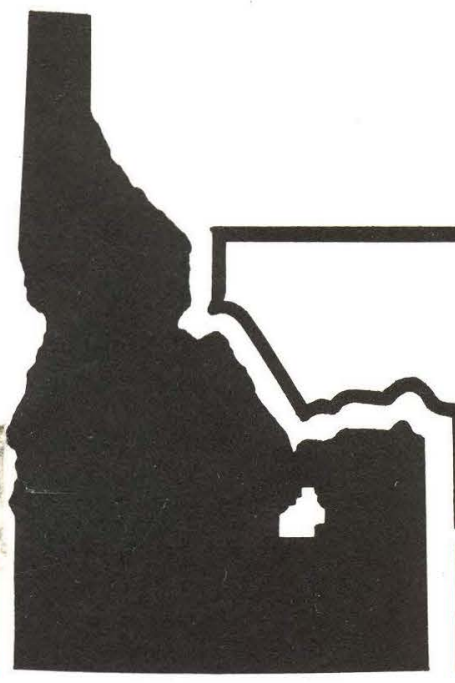

September 1978

EG\&G Idaho, Inc.

IDAHO NATIONAL ENGINEERING LABORATORY

\section{DEPARTMENT OF ENERGY}

PDF Available 
TFBP-TR-289

for U.S. Nuclear Regulatory Commission

\title{
REACTIVITY INITIATED ACCIDENT TEST SERIES RIA SCOPING TEST QUICK LOOK REPORT
}

\author{
Z.R. MARTINSON \\ R.S. SEMKEN \\ T. INABE \\ R.H. SMITH \\ T.F. COOK \\ A.D. APPELHANS
}

September 1978

EG\&G Idaho, Inc.

IDAHO NATIONAL ENGINEERING LABORATORY

\section{DEPARTMENT OF ENERGY}




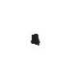


TFBP-TR - 289

September 1978

\section{REACTIVITY INITIATED ACCIDENT TEST SERIES}

RIA SCOPING TEST

OUICK LOOK REPORT

Z. R. Martinson

R. S. Semken

T. Inabe

R. H. Smith

T. F. Cook

A. D. Appelhans

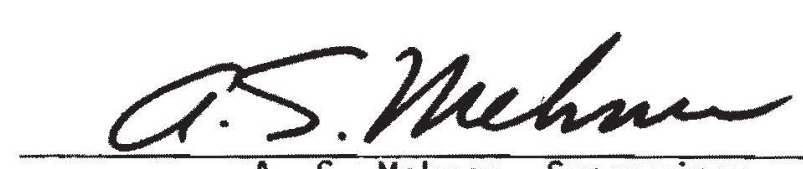

A. S. Mehner, Supervisor PCM, RIA, and IE Tests Section

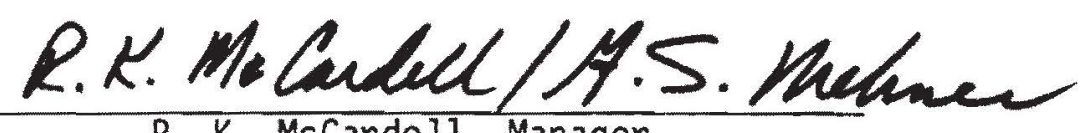

R. K. McCarde 11, Manager

Experiment Specification and Analys is Branch

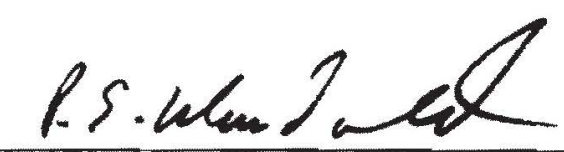

P. E. MacDonald, Manager

Light Water Reactor Fue 1 Research Division 


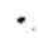




\section{CONTENTS}

SUMMARY. . . . . ..................... 1

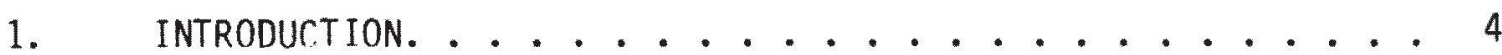

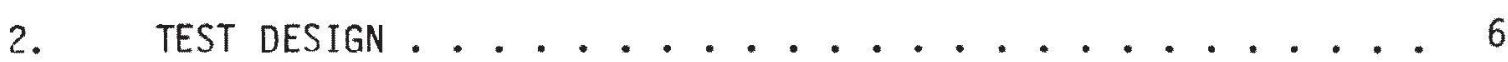

2.1 Test Train............... 6

2.2 Instrumentation............. 6

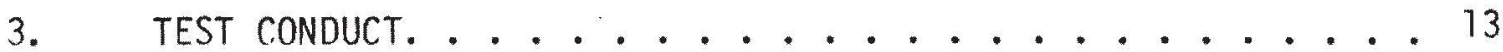

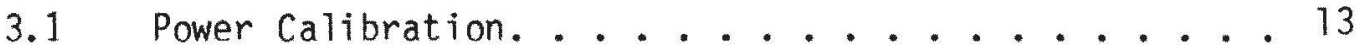

3.2 Fuel Rod Conditioning. . . . . . . . . . 19

3.3 Control Rod Worth and Transient Checkout. . . . . 19

3.4 Power Burst Testinq. .............. 20

3.5 Power Bursts ................ 21

3.5.] RIA-ST-] Power Burst. . . . . . . 21

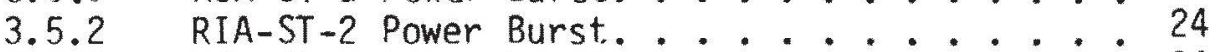

3.5.3 RIA-ST-3 Power Burst. . . . . . . . . 24

3.5.4 RIA-ST-4 Power Burst. .......... 24

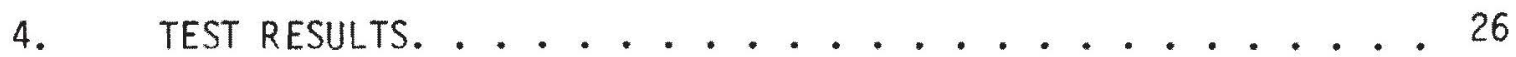

4.1 Calorimetric Applicability........... 26

4.2 Failure Threshold. . . . . . . . . . 3 I.

4.3 Pressure Pulse Generation. . . . . . . . . 31

4.4 Instrument Sensitivity ............ 36

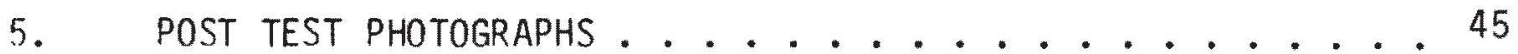

6. FISSION PRODICT DETECTOR. ........................ 50

7. CONRLUSIONS ........................ 53

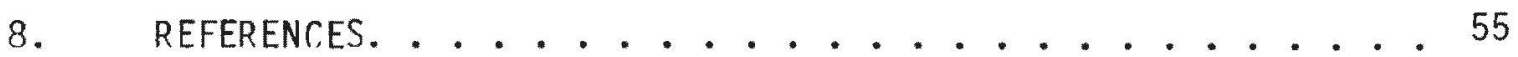

FIGURES

1. Schematic representation of RIA Scoping Test train showing approximate instrument locations........... 10 
2. Peak rod power as a function of core power (RIA-ST-1,

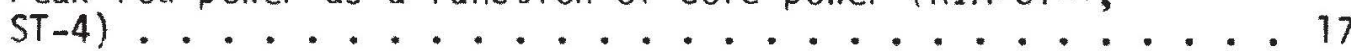

3. SPND .686 Current vS peak rod power (RIA-ST-1, ST-4). . . 17

4. SPND .457 Current vS peak rod power (RIA-ST-1, ST-4). ... 18

5. SPND .229 Current vs peak rod power (RIA-ST-1, ST-4). . . 18

6. Coolant pressure vs. time at the flow shroud inlet and outlet during the first power burst of RIA-ST-1 as indicated by the 69 MPA EG\&G pressure transducers. ......... 23

7. Shroud coolant flowrate at the inlet during the first power

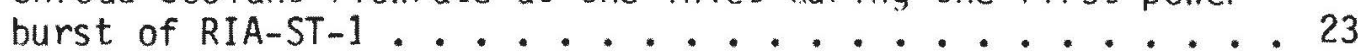

8. Comparison of PBF core power during RIA-ST-3 as derived from $0.229 \mathrm{~m}$ SPNO and TR-1 core ionization chambers. . . . . 29

9. Coolant pressure vs. time at flow shroud in let and out let during the second power burst of RIA-ST-1 as indicated by the $69 \mathrm{MPa}$ EG\&G pressure transducer .......... 32

10. Response of the $17 \mathrm{MPa}$ EG\&G pressure transducer during the power burst of RIA-ST-4....................... 34

11. Response of the upper $69 \mathrm{MPa}$ EG\&G pressure transducer during

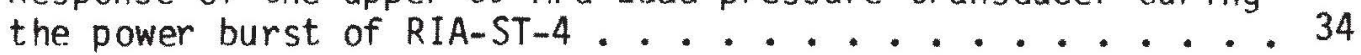

12. Response of the $17 \mathrm{MPa}$ Bell \& Howe 11 pressure transtucer during the power burst of RIA-ST-4 .............. 35

13. Response of the lower $69 \mathrm{MPa}$ EG\&G pressure transducer during the power burst of RIA-ST-4.............. 35

14. Radiation sensitivity of the $69 \mathrm{MPa}$ EG\&G pressure transducer

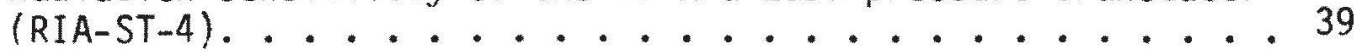

15. Radiation sensitivity of the $17 \mathrm{MPa}$ EG\&G and Kaman pressure trans ducers (RIA-ST-1, Burst ?) .......... 39

16. Radiation sensitivity of the $17 \mathrm{MPa}$ Bell \& Howell pressure transducer (RIA-ST-1, Burst 2)............ 41

17. Radiation sensitivity of the linear variable differential

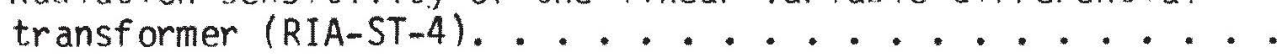

18. Radiation sensitivity of the Type $S$ thermocouple (RIA-ST-1,

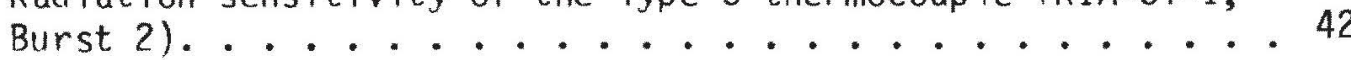

19. Radiation sensitivity of the strain gages (RIA-ST-1,

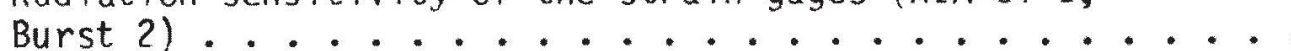


20. Flowmeter response during the power burst and rod failure of

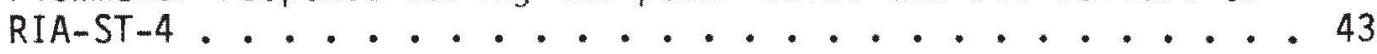

21. Posttest photograph of fue 1 rod from RIA-ST-2 between the 0.370 and $0.470 \mathrm{~m}$ rod elevations. . . . . . . . . . 46

22. Posttest photograph of fuel rod from RIA-ST-2 hetween the 0.520 and $0.600 \mathrm{~m}$ rod elevations ........... 46

23. Posttest photograph of fue 1 rod from RIA-ST-2 between the 0.675 and $0.780 \mathrm{~m}$ rod elevations ................ 47

24. Posttest photograph of fuel rod from RIA-ST-3 hetween the 0.360 and $0.450 \mathrm{~m}$ rod elevations ..................... 48

25. Posttest photograph of fuel rod from RIA-ST-3 near $0.600 \mathrm{~m}$

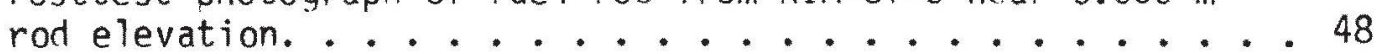

26. Posttest photograph of fuel rod from RIA-ST-3 near $0.660 \mathrm{~m}$

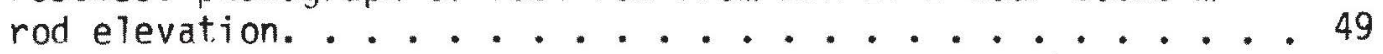

27. Gross aamma count rate (150-3400 KeV range) durina Scoping Test 1 Burst 2................. 51

28. Gross gamma count rate (150-3400 KeV range) during Scoping

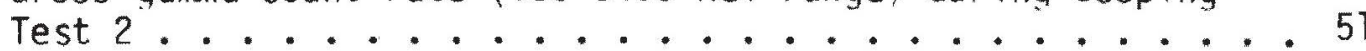

29. Gross gamma count rate $(150-3400 \mathrm{KeV}$ range) during Scoping Test 3. No failure indicated ............. 52

30. Gross gamma count rate $(150-3400 \mathrm{KeV}$ range) during Scoping

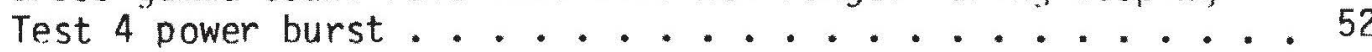

\section{TABLES}

I. RIA Scoping Test Fuel Rod Design Characteristics . ...... 7

II. Test Train Instrumentation For RIA-ST. . . . . . . . . 9

III. RIA Scoping Test Conduct ................ 14

IV. Sumary of RIA-ST-1 Power Calibration Data . . . . . . 15

V. Sumary of RIA-ST-4 Power Calibration Data . . . . . . . 16

VI. RIA Scoping Test Summary . . . . . . . . . . . . 22

VII. Summary of Fuel Rod Energy Data. . . . . . . . . . . . 28

VIII. Pressure Data From RIA-ST-4 Power Burst. . . . . . . . . . 37 


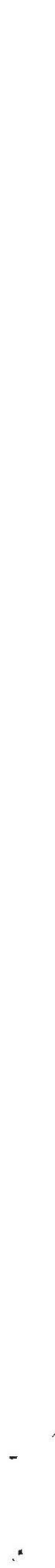


SUMMARY

The Reactivity Initiated Accident Scoping Test. (RIA-ST) was successfully completed August 30, 1978. The test was introductory to the RIA Series 1 tests and was designed to investigate and resolve several anticipated problem areas prior to performance of the first test of the series, Test RIA 1-1. The RIA Scoping Test, as performed, consisted of four separate sinqle-rod experiment phases. The first three phases were performed with shrouded fuel rods of 5.8 wt.\% enrichment. They were subjected to power hursts resulting in total fuel surface energies ranging from 205 to $261 \mathrm{cal} / \mathrm{g}$ at the axial peak elevation. The fourth phase consisted of a $20 \mathrm{wt} . \%$ enriched, shrouded fuel rod which was subjected to a power hurst that deposited a total radially averaged energy of $527 \mathrm{cal} / \mathrm{g}$.

The primary objectives of the Scoping Test were defined as follows:

(1) Determine the applicability of extrabolating low-power steady state calorimetric measurements and self-powered neutron detector (SPND) output to determine fuel rod enerqy depositions during a power burst.

(2) Determine the energy deposition failure threshold for unirradiated fuel rods at BWR hot-startup conlant conditions.

(3) Determine the magnitudes of possible pressure pulses resulting from rod failure.

(4) Determine the sensitivity of the test instrumentation to high transient radiation exposures.

In general, the energy deposition values for the Scopina Test derived from the SPND output were $25 \%$ higher than those obtained from the core ion chamber data. Determining which values are correct will 
require radiochemical analysis of the fuel rods which will take several months. At present, it appears that the SPND derived eneraies are in error because of excellent agreement between the calculated and measured power calibration results and the agreement between the predicted failure threshold and that seen using the core ion chamber derived energies.

Meeting the second objective was accomplished during the first three test phases by subjecting the fuel rods to energy depositions which bracketed the failure threshold. The failure threshold in terms of total pellet surface energy at the axial flux peak was found to be between $218 \mathrm{cal} / \mathrm{g}$ where no rod failure occurred and $256 \mathrm{cal} / \mathrm{g}$ where rod failure did occur. The experiment predictions indicated that the failure threshold would be $262 \mathrm{cal} / \mathrm{g}$ at the pellet surface.

Only the fourth experiment phase $(527 \mathrm{cal} / \mathrm{g})$ resulted in a pressure pulse upon rod failure. The hest indication of source pressure was the reading from a $69 \mathrm{MPa}$ EG\&G pressure transducer at the flow shroud inlet. This pressure transducer indicated a pressure pulse upon rod failure of $28.2 \mathrm{MPa}$ with a rise time of $1.6 \mathrm{~ms}$. The source pressure was attenuated considerably outside the shroud region as indicated by pressure transducers in the upper plenum of the in-pile tube and in the flow bypass region. The maximum pressure indicated outside the flow shroud was $2.1 \mathrm{MPa}$.

In genera1, instrumentation sensitivity to radiation was minimal. The most significant instrumentation problem during the power bursts was a false flowrate indication by the flow turbines. This problem is being examined. The Kaman and Bell \& Howell pressure transducers showed the least sensitivity to radiation of the pressure measurement devices. The EG\&G transducers were most sensitive. The locked linear variable differential transformer (LVDT) aave no indication of radiation sensitivity as its response during the burst was a straight line. The strain gages were verv sensitive to radiation, 
indicating a strain increase of $70 \%$ with the second burst of RIA-ST-1. The Type $S$ thermocouple did not exhibit siqnificant radiation sensitivity.

In addition, the RIA Scoping Test has provided data on the consequences of fuel rod failure during a RIA event at BWR hot startup conditions. Posttest examination of the fuel rods from the first two phases of the test revealed large quantities of $\mathrm{UO}_{2}$ fuel missing from the cladding. Fuel rod failures for energy depositions near the failure threshold in previous closed capsule tests without forced coolant flow resulted in only a slight amount of fuel loss. 


\section{INTRODUCTION}

The Reactivity Initiated Accident Scoping Test (RIA-ST), performed in the EG\&G operated Power Burst Facility (PBF), was completed on August 30, 1978. The Scoping Test was the introductory test to the five planned PBF/RIA tests of Series $1[\mathrm{a}]$. The objectives of the RIA Series 1 tests are to determine the thresholds, modes, and consequences of fuel failure under RIA conditions as functions of eneray deposition, irradiation history, and fuel rod design. Each test will be performed with coolant conditions typical of commercial boiling water reactors (BWR) during hot-startup. With the completion of the RIA Scoping Test, four previously identified questions which relate to the successful performance of the RIA Series 1 tests have been addressed. The four questions which were to be answered by the RIA Scoping Test are: (1) Can low-power steady state calorimetric measurements and self-powered neutron detector output be extrapolated to determine fuel rod energy depositions during a power burst? (2) What is the energy deposition failure threshold for unirradiated fuel rods with BWR hot startup coolant conditions? (3) What is the magnitude of possible pressure pulses that can result from fuel rod failure in a water filled system? and (4) What is the sensitivity of the test instrumentation to high transient radiation exposures?

The RIA Scoping Test was originally comprised of five separate single-rod experiment phases designated as RIA-ST-1, RIA-ST-2, RIA-ST-3, RIA-ST-4, and RIA-ST-5. The RIA-ST-5 experiment was cancelled, and therefore will not be discussed in this report. Section?

[a] The Series 1 tests consist of Tests RIA 1-1, RIA ]-2, RIA ]-3, and RIA 1-6 (shrouded four-rod tests) and RIA 1-4 (a sixteen-rod cluster test). 
provides a brief description of the design of the four RIA Scoping Test experiments performed. Section 3 outlines the test conduct, providing results of the power calibrations and the magnitudes of the power bursts. Test results are presented in Section 4 in terms of the test objectives and where applicable are compared to the experimental predictions. Section 5 contains six photographs illustrating the posttest condition of the rods from RIA-ST-2 and RIA-ST-3. These two rods were subiected to energy depositions which bracket the failure threshold deposition. In Section 6, a brief discussion of the fission products detection subsequent to the test rod failures is presented, and finally, Section 7 provides conclusions. 


\section{TEST DESIGN}

The RIA Scoping Test as performed was comprised of four separate, single-rod experiment phases. The fuel rod for each phase was positioned in a separate flow shroud in the center of the PBF in-pile tube (IPT). The non-instrumented high-pressure spool pieces were installed in the loop piping. This section describes the design of the fue 1 rods, test assembly, and instrumentation associated with each experiment.

\subsection{Test. Train}

The four fuel rods used in the RIA Scoping Test experiment phases were designated as $800-1,800-2,800-3$, and 800-4, respectivelv. The nominal design characteristics of these rods are given in Tahle I. The fuel rods were fabricated from unirradiated cladding and fresh fuel pellets. The fuel pellets for Rods 800-1, 800-2, and 800-3 were ground down to fit in the available pressurized water reactor (PWR) cladding.

Individual zircaloy-4 flow shrouds, having a nominal inner diameter of $16.3 \mathrm{~mm}$ and an outer diameter of $22.6 \mathrm{~mm}$, surrounded Rods 800-1, 800-2, and 800-3. A zircaloy-4 flow shroud, having a nominal inner diameter of $19.3 \mathrm{~mm}$ and an outer diameter of $25.4 \mathrm{~mm}$, surrounded Rod 800-4. Fuel particle catch screens were installed at the inlet and outlet of the flow shroud for Rod 800-4.

The PBF single rod test train assembly was used for the RIA Scoping Test. In this test assembly, the fuel rod is held rigidly at the top, with the rod free to expand axially downward.

\subsection{Instrumentation}

The RIA Scoping Test instrumentation was intended for pressure pulse measurement, calorimetric measurement of the test rod power, and evaluation of instrumentation to be used in future RIA tests. There 


\section{TABLE I}

RIA SCOPING TEST FUEL ROD DESIGN CHARACTERISTICS

Characteristic

Fue 1

$$
\text { Material }
$$

Pellet $00(\mathrm{~mm})$

Pellet length (mm)

Pellet enrichment (wt, \%)

Density(\% TD)

Fuel stack length (m)

End configuration

Burnup

Cladding

Material

Tube $0 D(\mathrm{~mm})$

Tube wa 11 thickness (mm)
Rods 800-1, 2, 3

Rod $800-4$

$\mathrm{UO}_{2}$

9.3

15.49

20

93

0.914

Disher

0

$7 r-4$

10.73

0.61

Fuel Rod

$\begin{array}{lcc}\text { Overall length }(\mathrm{m}) & 1.0 & 1.0 \\ \text { Filler gas } & \text { Helium } & \text { Helium } \\ \text { Initial gas } & 0.103 & 3.79 \\ \text { pressure }(\mathrm{MPa}) & & \end{array}$


was no instrumentation installed on the test fuel rods. Table II surmarizes the instrumentation used for the RIA Scoping Test including information as to location, range, and response time. Figure 1 provides a schematic representation of the test train in the IPT flow tube showing the approximate locations of some of the test train instrumentation.

The test assembly instrumentation consisted of the followina:

(1) Three coolant pressure transducers; two located above the flow shroud outlet, and one connected to the flow shroud to measure normal system pressure and transient pressure pulses. Al1 these pressure transducers were operable through the four experiments.

(2) Two turbine flowmeters, mounted in series at the inlet of the flow shroud, to measure the shroud coolant flow. Both turbine flowmeters failed in the course of the test. One replacement was necessary.

(3) Four Chromel-Alumel (Type K) thermocouples; two mounted at the shroud inlet and two at the outlet, to measure the fuel rod coolant temperature at inlet and outlet. One inlet and one outlet thermocouple failed during the course of the test.

(4) Two differential copper-constantan (Type T) thermocouples mounted on the test train to measure the fuel rod coolant temperature rise. One of these was broken during a rod changeout.

(5) Three cobalt SPNDs located in one vertical column 30 dearees clockwise from the reactor north position at $0.229,0.457$, and $0.686 \mathrm{~m}$ above the bottom of the test fue 1 rod.

(6) One flux wire, mounted on the outer surface of the flow shroud (reactor north orientation), for each phase of the 
TABLE II

TEST TRAIN INSTRUMENTATION FOR RIA-ST

\begin{tabular}{|c|c|c|c|c|}
\hline Measurement & instrument & Instrument Location & Instrument Ranae & Resonnse Time (s) \\
\hline Coolant pressure & Pressure transducer & Upoer Dlenum & 0 to $69 \mathrm{MPa}$ & $3 \times 10^{-5}$ \\
\hline Coolant pressure & Pressure transilucer & Upper plenum & 0 to $17 \mathrm{MPa}$ & $3 \times 10^{-5}$ \\
\hline Conlant oressure & Pressure trans ducer & Connecter to shroud & 0 to $69 \mathrm{Mga}_{\mathrm{a}}$ & $3 \times 10-5$ \\
\hline Conlent flow & Turbine flow meters (2) & Inlet of flow shroud & 63 to $8>0 \mathrm{~cm}^{3} / \mathrm{spc}$ & $N / A$ \\
\hline $\begin{array}{l}\text { Conlant in let } \\
\text { temperature }\end{array}$ & Thermocoup les $|2|$ & Inlat of flow shroud & 300 to $600 \mathrm{~K}$ & $\mathrm{~N} / \mathrm{A}$ \\
\hline $\begin{array}{l}\text { Coolant outlet } \\
\text { temperature }\end{array}$ & Thermocoup les $(2)$ & Outlet of flow shroud & 300 to $500 \mathrm{k}$ & $N / A$ \\
\hline $\begin{array}{l}\text { Coolant differen- } \\
\text { tial temperature }\end{array}$ & Thermocouple pairs (2) & $\begin{array}{l}\text { Inlet and outlet of } \\
\text { flow shroud }\end{array}$ & $n$ to $20 \mathrm{k}$ & $N / A$ \\
\hline $\begin{array}{l}\text { Relative neutron } \\
\text { flux }\end{array}$ & Cobalt SPNDS (3) & $\begin{array}{l}1 \text { vertical column with } \\
\text { detectors at } 0.222^{\circ} \text {, } \\
0.457 \text {, and } 0.586 \mathrm{~m} \text { from } \\
\text { bottom of fuel stack }\end{array}$ & $N / A$ & $0.00 ?$ \\
\hline Neutron flax (IPT) & $\begin{array}{l}0.5 \% \text { cobalt wire } \\
\text { for Rods } 1 \text {, } 4 \text {, and } 5 \\
100 \% \text { cobalt wire } \\
\text { for Rods } 2 \text { and } 3[0]\end{array}$ & $\begin{array}{l}\text { Outer surface of flow } \\
\text { shroud (reactor North } \\
\text { orientation) }\end{array}$ & $N / A$ & $N / A$ \\
\hline Neutron flux (core) & $100 \%$ cohalt wire & PSF core periphery & $N / A$ & $N / A$ \\
\hline cladd inq elongation & LVDT & Bottom of fuel rod & -5 to $20 \mathrm{~mm}$ & 0,003 \\
\hline $\begin{array}{l}\text { padiation } \\
\text { sansitivity }\end{array}$ & Pressure transducer 14 & Uoper olenum & $\begin{array}{l}0 \text { to } 17 \mathrm{MPa}(3) \\
0 \text { to } 69 \mathrm{MPa}\end{array}$ & 0.002 \\
\hline $\begin{array}{l}\text { Radiation } \\
\text { sensitivity }\end{array}$ & Pressure transducer (1) & Flow hupass reaion & 0 to $17 \mathrm{MPa}$ & 0.002 \\
\hline $\begin{array}{l}\text { Radiation } \\
\text { sensitivity }\end{array}$ & LVDT & Lower olenum & $0 \pm 17.7 \mathrm{~mm}$ & 0.003 \\
\hline $\begin{array}{l}\text { IPT head } \\
\text { temperature }\end{array}$ & Tyoe $k$ thermocoud le & IPT head & 30 to $600 \mathrm{~K}$ & $N / A$ \\
\hline Shroud strin & Strain gavae (2) & Flow shroud of Rod 1 only & $-3 \%+0+3 \%$ & Not known \\
\hline [a] Rot 1 refors to & Rod $800-1$, Rod $?$ refers & to Rod $800-2$, etc. & & \\
\hline
\end{tabular}


$17 \mathrm{MPa} B \& \mathrm{H}$ Pressure

Transducer

$69 \mathrm{MPa}$ EG\&G Blocked

Pressure Transducer

Filter Adaptor with Holes

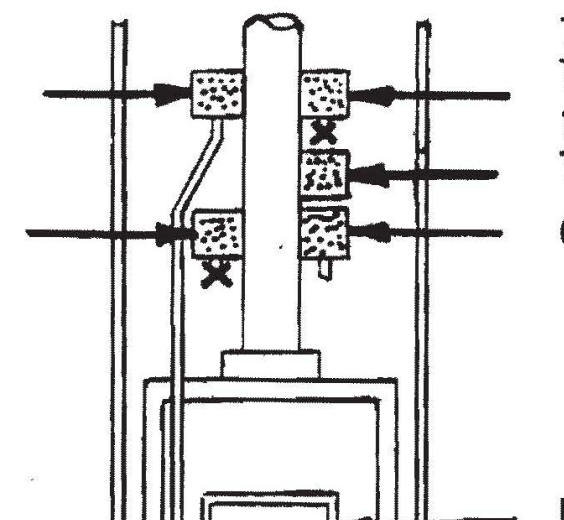

17 MPa EG\&G Blocked Pressure Transducer

$17 \mathrm{MPa}$ Schaevitz Pressure

Transducer

$69 \mathrm{MPa}$ EG\&G Pressure Transducer

Upper Particle Filter

Flow Tube

Transducer

Orifice Plate

17 MPa Kaman Blocked Pressure Transducer

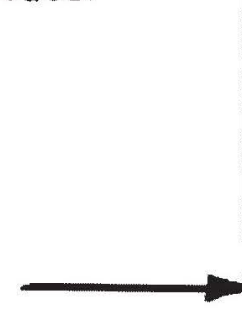

$69 \mathrm{MPa}$ EG\&G Pressure

Upper Flow Meter

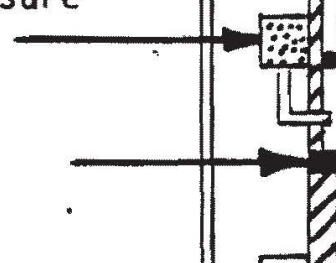

Linear Variable Differential Transformer (LVDT)

Blocked LVDT

Lower Flow Meter

17 MPa EG\&G Pressure

Rod Support

Fuel Rod

Flow Shroud

Blocked LVDT
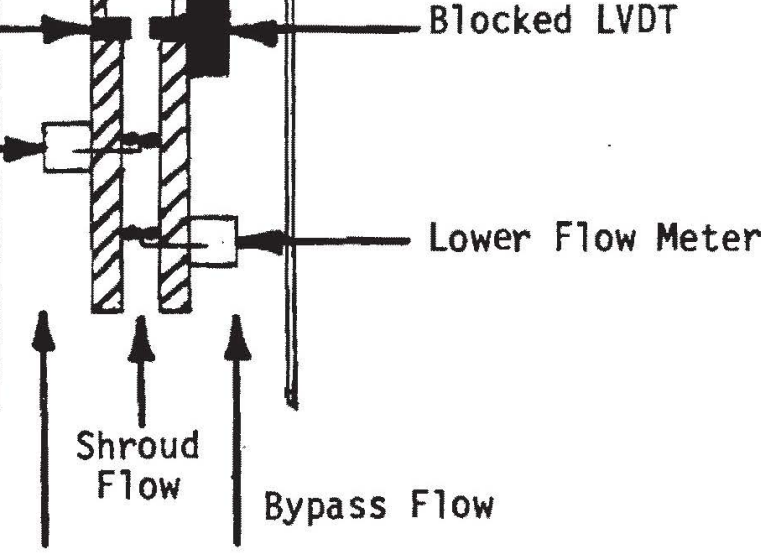

Fig. 1 Schematic representation of RIA Scoping Test train showing approximate instrument locations. 
test $10.51 \%$ Co-A 1 wire for Rods $800-1$ and $800-4$, and $100 \%$ cobalt wire for Rods $800-2$ and 800-31.

(7) One Kaman pressure transducer, and two EG\&G DC excited strain post type pressure transducers, located in the flow bypass region for radiation sensitivity evaluation. The pressure transducers were sealed to eliminate instrument response due to coolant pressure chances. The pressure transducers were backfilled with helium to a cold pressure of $2.07 \mathrm{MPa}$.

(8) One Bell and Howe 11 pressure transducer and one Schaevitz pressure transducer located above the flow shroud outlet for instrument evaluation. The Schaevitz transducer failed prior to running the first experiment. The Bell and Howell pressure transducer was connected via a tube welded to the flow shroud at the axial power peak elevation for RIA-ST-4.

(9) An LVDT mounted at the bottom of the fuel rod to measure changes in the axial length of the rod. This LVDT failed prior to RIA-ST-1 and its housing was removed after RIA-ST-? was completed in order to improve the pressure pulse measurements for RIA-ST-4.

(10) An LVDT with the core locked in position, located below the fuel rod for radiation sensitivity evaluation.

(11) One Type S thermocouple, located on the flow shroud, for radiation sensitivity evaluation. This thermocouple was only connected for RIA-ST-1.

(12) Two Type $k$ thermocouples to measure the IPT head temperature.

(13) Two strain gages, located on the flow shroud, for ratiation sensitivity evaluation. These were connected only during RIA-ST-1. 
Plant instrument data recorded along with the test train instrument data were the followina:

(1) NMS-3 ion chamber

(2) PPS-1, PPS-2, PPS-3, PPS-4 ion chambers

(3) TR-1, TR-2 ion chambers

(4) EV-1, EV-2 ion chambers

(5) In-pile tube system pressure

(6) In-pile tube $\Delta p$

(7) Loop flow rate

(8) Loop fission product detection system

(9) Core fuel rod LVDTs (?)

(10) Reactor vessel strain gages (2)

(11) Loop pressure transducers (9)

In addition, a 100\% cobalt flux wire was installed in the reflector region of the core. A new cobalt flux wire was installed during each scheduled reactor shutdown. A closed-circuit television camera was positioned to view the Heise 1oop pressure gage and the image was displayed on a television monitor at the PBF control room.

The test assembly and plant instrument data were recorded on the PBF Data Acquisition and Reduction System (PBF/DARS), Surveillance System (SS), and Experiment and Analvs is System (E\&A). 


\section{TEST CONDUCT}

The RIA Scoping Test as performed was comprised of the four separate, single-rod test phases designated as RIA-ST-1, RIA-ST-2, RIA-ST-3, and RIA-ST-4. Each of the single-rod experiments was proceeded by a non-nuclear heat up and interspersed with a number of instrument status checks as specified in the RIA Scoping Test Experiment operating Specification [1]. The purpose of these instrument verification procedures was to identify failed or out-of-range instrumentation so that corrective action could be initiated hefore proceeding with the test and to insure that instrumentation critical to the experiment was operable. Table III summarizes the as performed activities associated with RIA-ST-1 through RIA-ST-4. Several revisions were made to the RIA-ST Experiment Operating Specification during the test. The revisions are described in Document Revision Request (DRR) forms.

The nuclear operational phases of the test are reviewed below.

\subsection{Power Calibration}

The ohjective of the power calibration portion of RIA-ST-1 and RIA-ST-4 was to intercalibrate the thermal-hydraulically determined fuel rod power with reactor neutron detecting chambers and the SPNDS mounted on the test train. The on-line power calibrations were accomplished by measuring the coolant pressure, coolant inlet temperature, coolant temperature $r$ ise, and experiment flow. An axial peak-toaverage neutron flux ratio of 1.36 was used. The nominal coolant conditions for the power calibration phases were $538 \mathrm{~K}$ - inlet temperature, $6.45 \mathrm{MPa}$ IPT pressure, and $760 \mathrm{~cm}^{3} / \mathrm{s}$ experiment flow. The results of the power calibration portion of RIA-ST-1 and RIA-ST-4 are summarized in Tables IV and $V$ and Figures 2 through 5. Power calihration conversion ratios for the test fuel rods of 2.2 and $5 . ? \mathrm{~kW} / \mathrm{m}$ per MW of PBF core power were measured for RIA-ST-1 and RIA-ST-4, respectively. Reactor physics calculations had predicted a power calihration conversion ratio of $2.15 \mathrm{~kW} / \mathrm{m}$ per MW of PBF core power for the $5.8 \%$ enriched rods used in RIA-ST- 1 . 
TABLE III

RIA SCOPING TEST CONDUCT

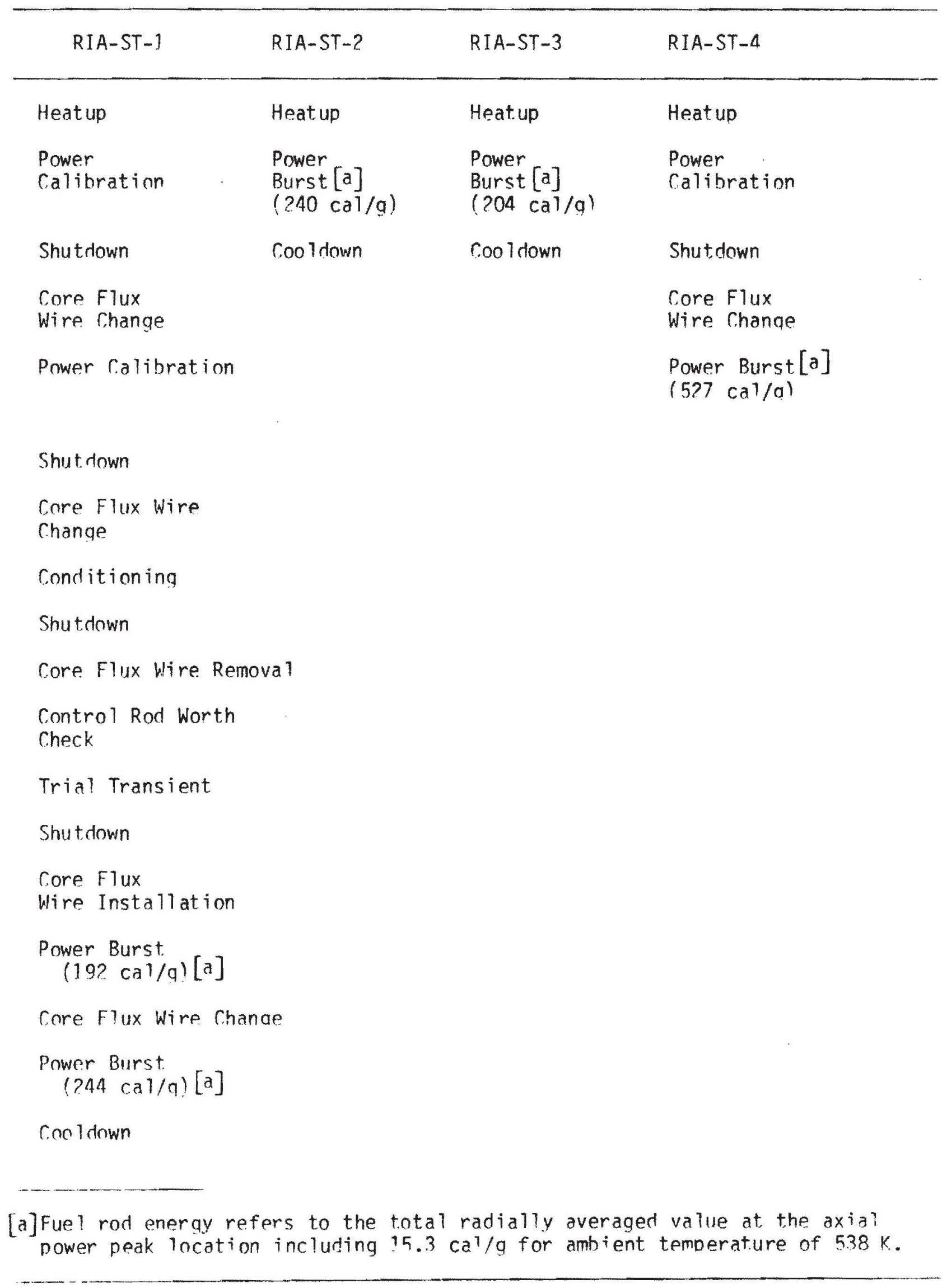


TABLE IV

SUMMARY OF RIA-ST-1 POWER CALIBRATION DATA

\begin{tabular}{|c|c|c|c|c|c|c|}
\hline $\begin{array}{l}\text { Reactor } \\
\text { Power } \\
\text { (MW) } \\
\end{array}$ & $\begin{array}{l}\text { Test Rod } \\
\text { Peak Power } \\
(\mathrm{kW} / \mathrm{m}) \\
\end{array}$ & $\begin{array}{l}\text { Axial Midplane } \\
\text { SPND Current } \\
(n A)\end{array}$ & $\begin{array}{c}\text { System Coolant } \\
\text { Pressure } \\
(\mathrm{MPa}) \\
\end{array}$ & $\begin{array}{l}\text { Coolant } \\
\text { Flow Rate } \\
\left(\mathrm{cm}^{3} / \mathrm{s}\right) \\
\end{array}$ & $\begin{array}{c}\text { Coolant Inlet } \\
\text { Temperature } \\
(\mathrm{K})\end{array}$ & $\begin{array}{c}\text { Temperature Rise } \\
\text { Across Experiment } \\
\text { (K) }\end{array}$ \\
\hline 5.5 & 14.6 & 48.4 & 6.36 & 754.0 & 539.7 & 3.3 \\
\hline 8.6 & 22.3 & 70.8 & 6.42 & 769.5 & 538.2 & 4.9 \\
\hline 11.2 & 28.6 & 108.4 & 6.43 & 759.1 & 540.3 & 6.3 \\
\hline 11.2 & 28.3 & 106.7 & 6.42 & 768.1 & 538.4 & 6.2 \\
\hline 14.1 & 35.0 & 136.0 & 6.43 & 752.0 & 538.1 & 7.8 \\
\hline 14.3 & 35.4 & 138.8 & 6.43 & 750.4 & 537.8 & 7.9 \\
\hline 16.9 & 41.2 & 162.0 & 6.42 & 758.7 & 537.7 & 9.1 \\
\hline 16.9 & 40.9 & 163.3 & 6.43 & 756.0 & 537.9 & 9.0 \\
\hline 19.8 & 46.9 & 187.0 & 6.42 & 760.5 & 538.6 & 10.3 \\
\hline 21.8 & 51.1 & 201.3 & 6.41 & 767.9 & 538.3 & 11.1 \\
\hline 19.8 & 47.2 & 183.8 & 6.43 & 752.7 & 538.4 & 10.4 \\
\hline 16.9 & 40.9 & 163.7 & 6.42 & 763.0 & 536.7 & 9.0 \\
\hline 14.3 & 34.7 & 138.7 & 6.42 & 766.8 & 537.4 & 7.6 \\
\hline 11.4 & 28.5 & 111.2 & 6.42 & 764.7 & 536.3 & 6.3 \\
\hline 8.9 & 22.5 & 85.7 & 6.43 & 755.0 & 536.6 & 5.0 \\
\hline 5.7 & 15.4 & 56.5 & 6.42 & 766.0 & 536.0 & 3.4 \\
\hline 2.8 & 7.9 & 28.3 & 6.43 & 749.6 & 535.0 & 1.8 \\
\hline
\end{tabular}


TABLE $V$

SUMMARY OF RIA-ST-4 POWER CALIBRATION DATA

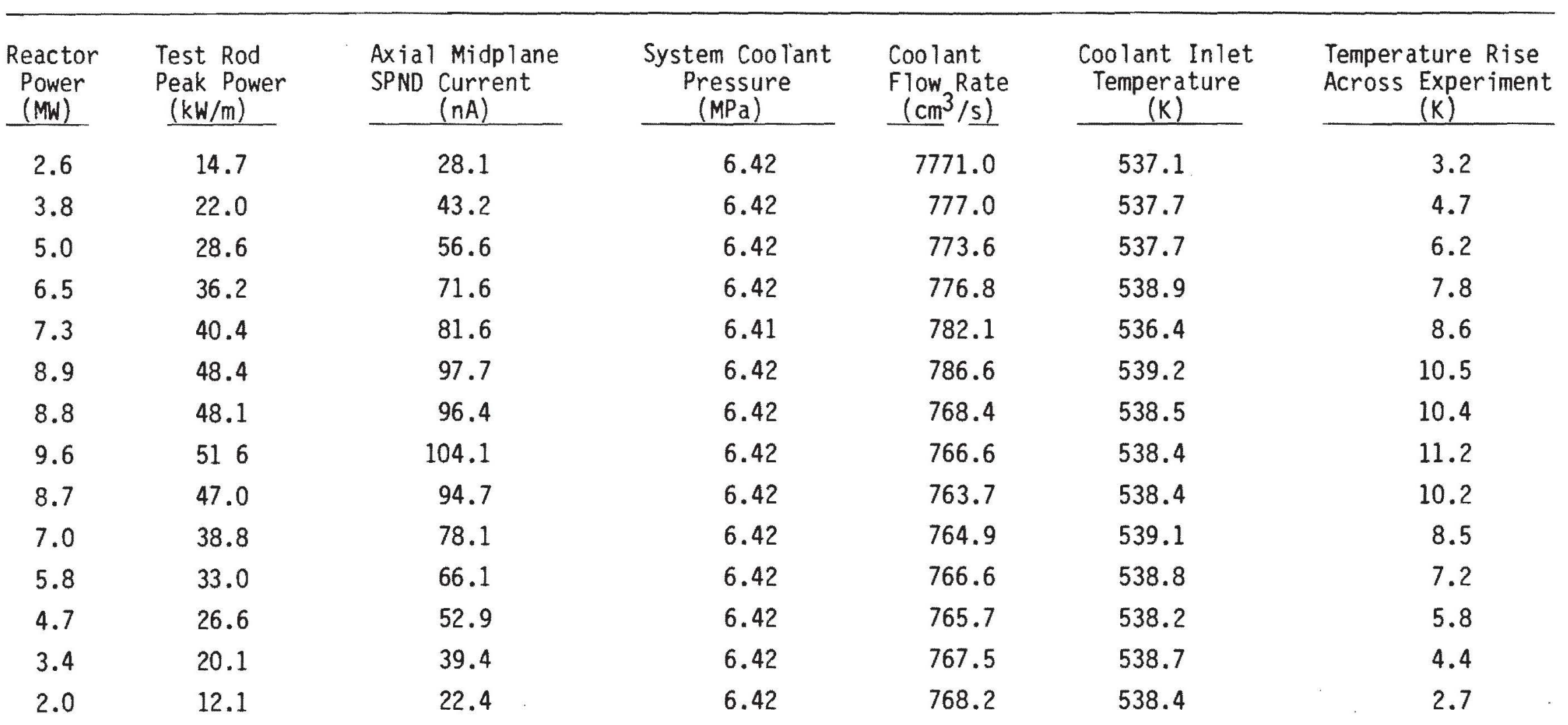




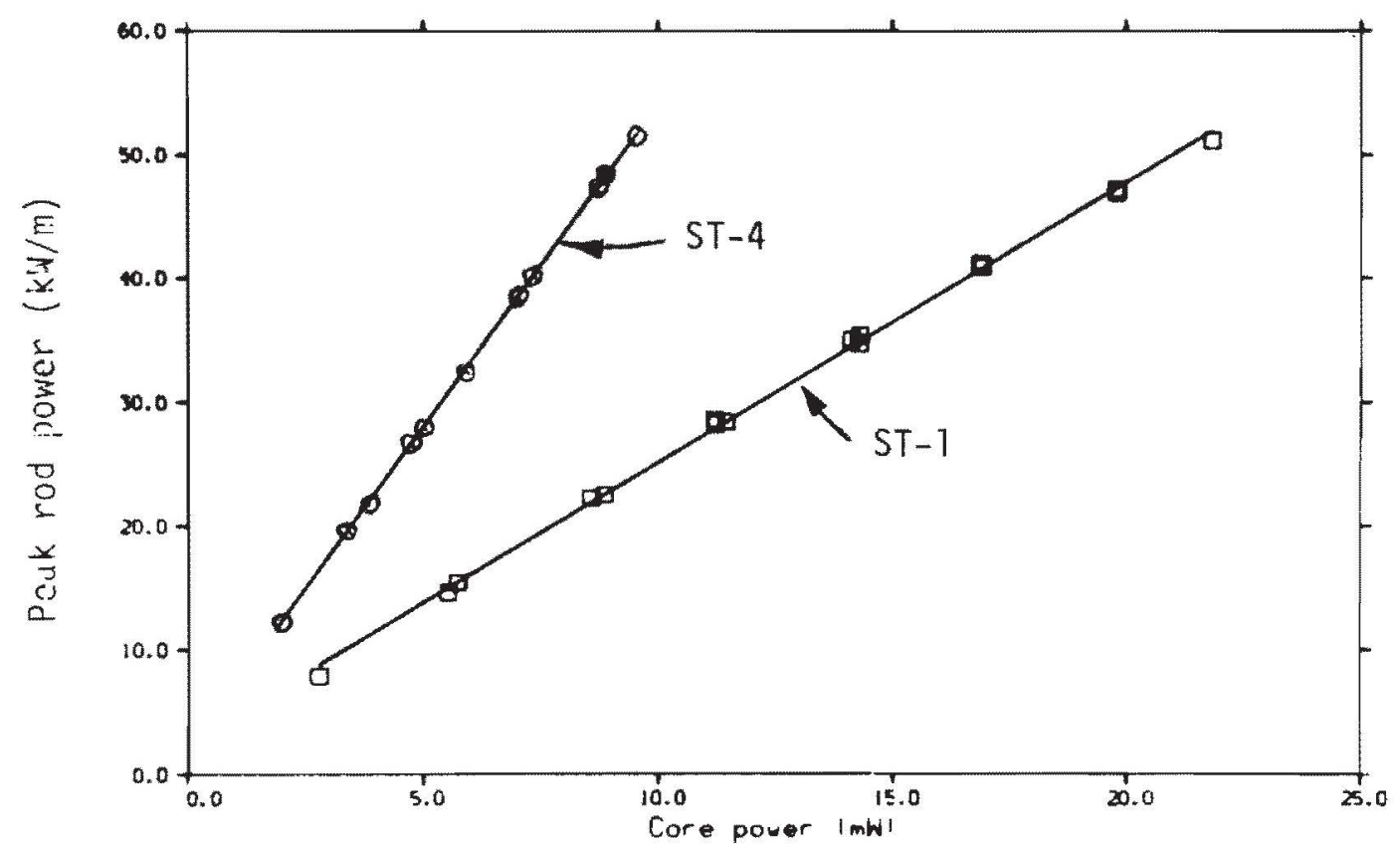

Fig.2 Peak rod power as a function of core power (RIA-ST-1, ST-4)

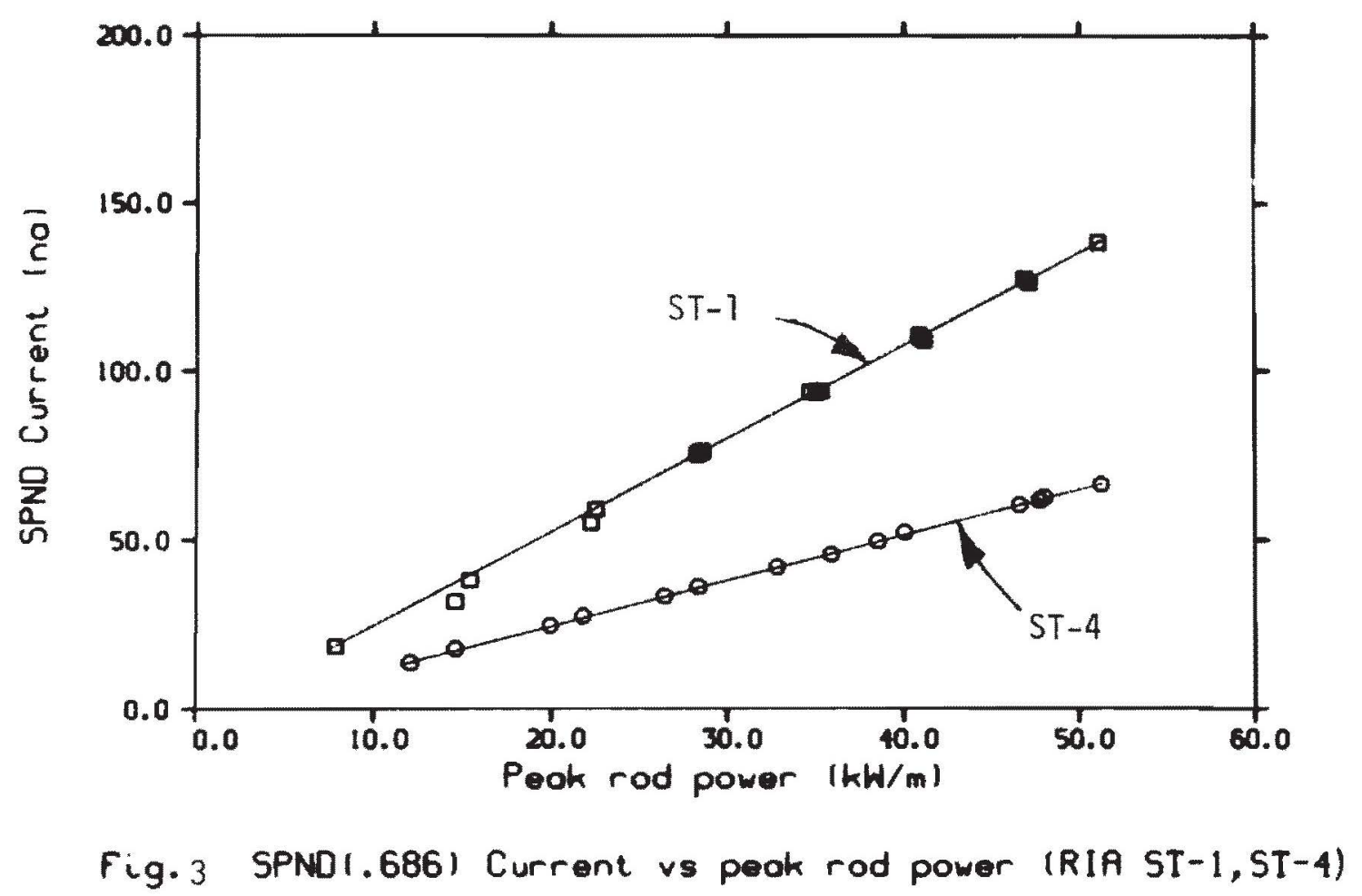




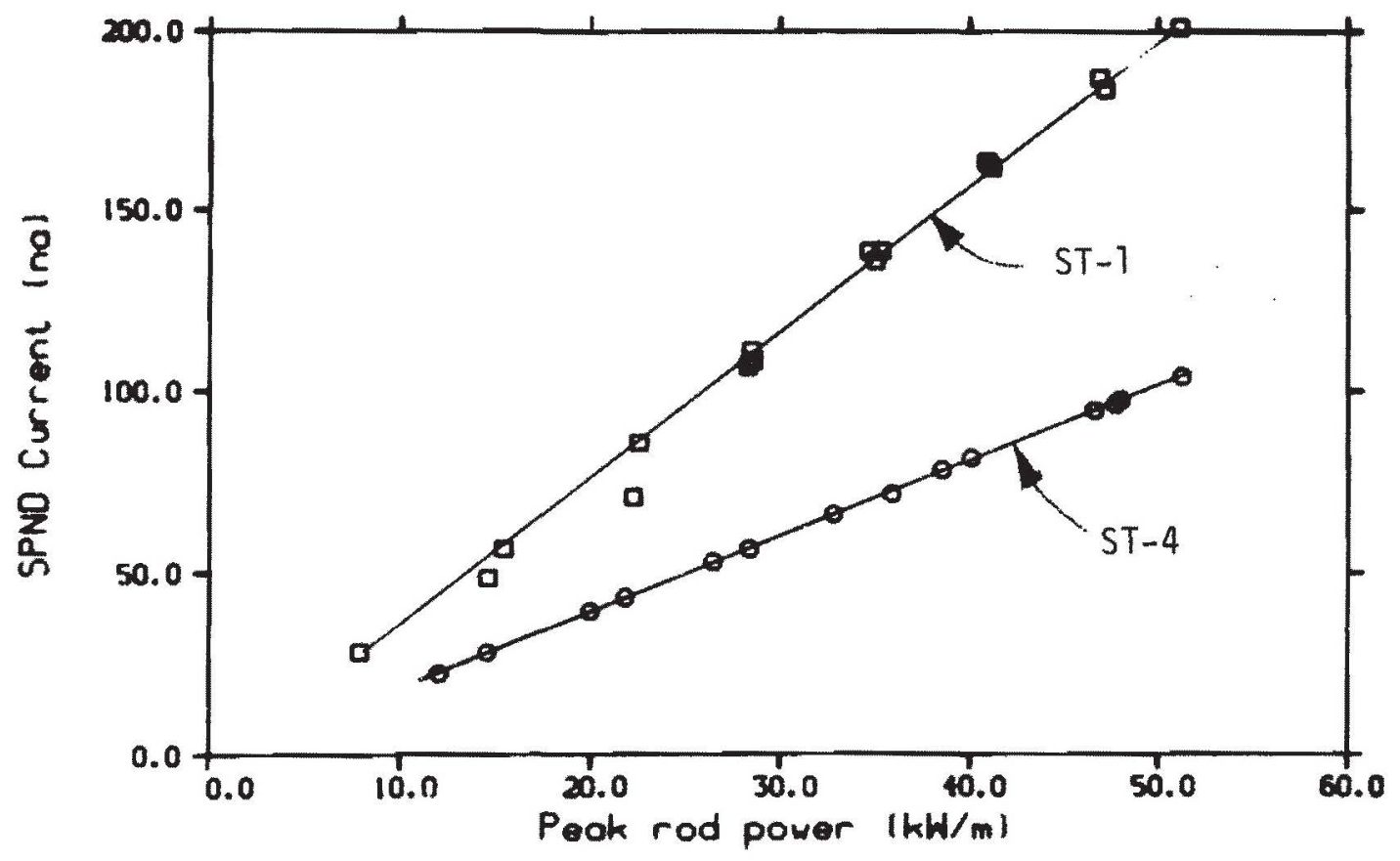

Fig. 4 SPNDI.457) Current vs peok rod power (RIA ST-1, ST-4)

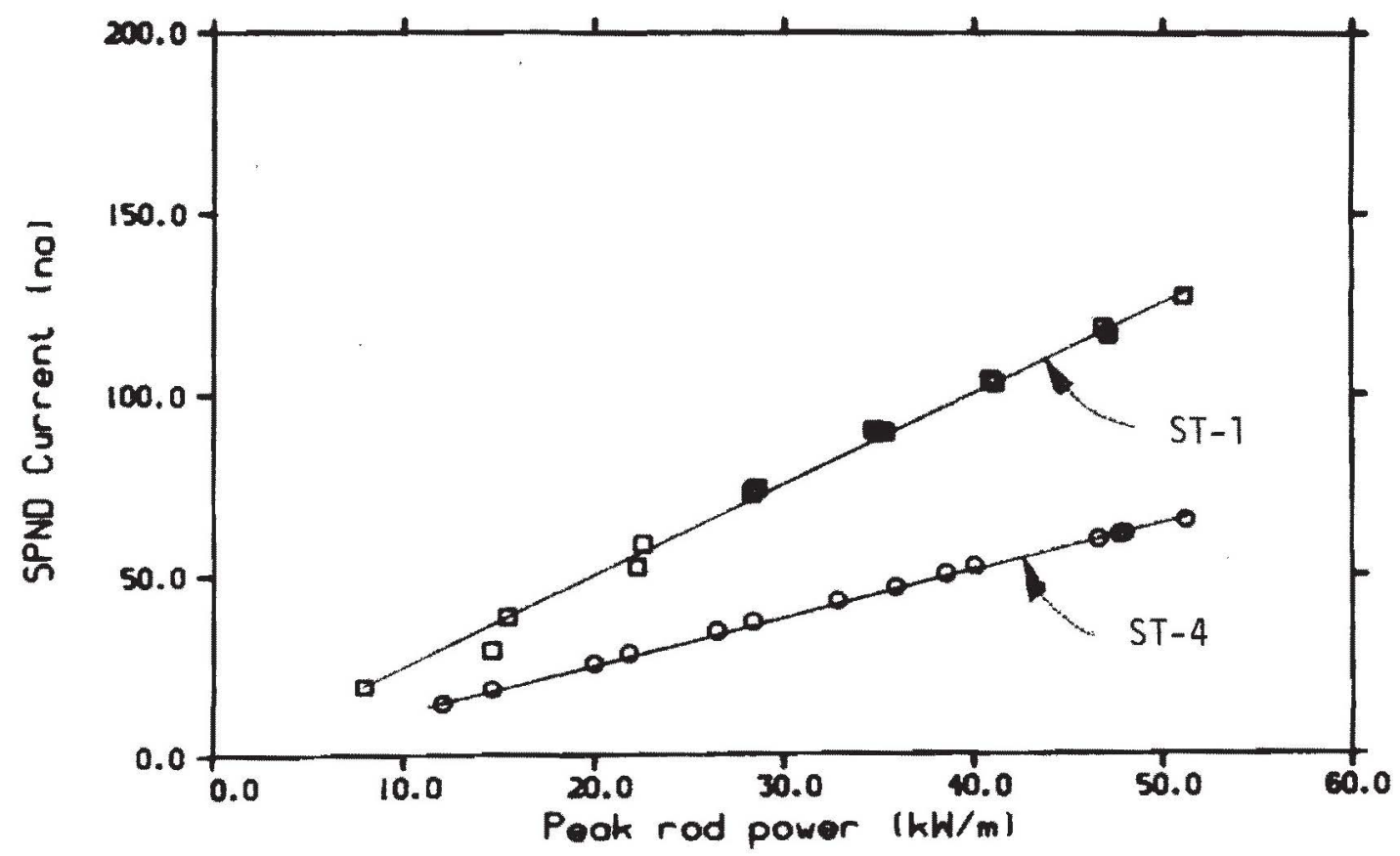

Fig. 5 SPND (.229) Current vs peok rod power (RIA ST-1, ST-4) 


\subsection{Fuel Rod Conditioning}

The objectives of the conditioning portion of RIA-ST-1 were to buildup the fission product inventory of the fuel rod to assure cladding failure indication by the fission product detection system during the transient testing and to cause fuel cracking and fuel relocation. The conditioning phase consisted of 4 power cycles. Durina each cycle the fuel rod peak power was increased slowly to $52 \mathrm{~kW} / \mathrm{m}$, held constant for 5 minutes, and then slowly reduced to $3 \mathrm{~kW} / \mathrm{m}$ and held constant for 5 minutes. The maximum power ramp rate was $3 \mathrm{~kW} / \mathrm{m}$ per minute. The nominal operating conditions were $538 \mathrm{~K}$ inlet temperature, $6.45 \mathrm{MPa}$

IPT pressure, and $760 \mathrm{~cm}^{3} / \mathrm{s}$ experiment flow. The reactor was shut. down after the fuel rod conditioning was completed to replace the core flux wire.

\subsection{Control Rod Worth and Transient Checkout}

Control rod reactivity worth checks and a trial reactor transient were performed after the power calibration and conditioning. The control rod reactivity worth checks were intended to intercalibrate the control rods and transient rods for reactivity worths of 0.75 , 1.5, and 1.75 do 11 ars. A reactivity meter was used to measure the reactivity worth of the transient rods during transient rod insertion. The control rods were intercalibrated with the transient rods by determining the control rod position required for reactor criticality with the transient rods inserted in the core the required amount. Actual power bursts were not performed for the 1.5 and 1.75 do 11 ar reactivity measurements. A trial power burst $11.7 \mathrm{~s}$ period - 13 MW peak power) was performed for the 0.75 dollar reactivity measurement to verify the control rod and transient rod worth measurements indicated by the reactivity meter. The loop operating conditions in this phase were $538 \mathrm{~K}$ inlet temperature, $6.45 \mathrm{MPa}$ coolant pressure, and $760 \mathrm{~cm}^{3} / \mathrm{s}$ shroud flow. Results indicate that the accuracy of the reactivity meter measurements $( \pm 0.10$ do 11 ars $)$ was not adequate to permit determination of the actual control rod positions for performing a pre-selected power burst. 


\subsection{Power Burst Testing}

A total of five power bursts, excluding the previously discussed trial transient, were run in the course of the RIA Scoping Test. Reactor primary coolant conditions for each were nominaly 15,000 gpm, $295 \mathrm{~K}$ at the inlet, and atmospher ic pressure. The test loop conditions for each of the power bursts were nominally $85 \mathrm{~cm}^{3} / \mathrm{s}, 538 \mathrm{~K}$ at the flow shroud inlet, and 6.45 $\mathrm{MPa}$. Each transient was initiated by the following sequence of events.

(1) The reactor was made critical at about $100 \mathrm{~W}$ for determination of the low power critical position of the control rods.

(2) From this position the control rods were withdrawn an amount required to establish a reactor transient period of approximately $10 \mathrm{~s}$. The reactor power was allowed to increase until the "chamber operable" light indicated that the plant protective chambers were functioning proper ly. Immediately upon reaching this level, the control rods were inserted an amount required to make the reactor subcritical causing the power to rapidly decrease.

(3) The transient rods were then drawn into the core to a position representative of the reactivity insertion required for the power burst.

(4) The control rods were then withdrawn to make the reactor critical at a low power level. The reactivity inserted by the withdrawal of the control rods and the worth of the transient rods was compared to assure the increment of control rod withdrawal determined for the power burst was not grossly in error. 
(5) The control rods were adjusted, if required, to the increment of withdrawal determined for the desired reactivity insertion.

(6) The transient rods were then fully inserted into the core.

(7) The power burst was initiated manually by firing the transient rods, rapidly removing poison from the core. The reactor was set to scram at 0.15 seconds after transient initiation or at 9,900 MW for the first burst and at 0.09 seconds or at $16,500 \mathrm{MW}$ for the subsequent four power bursts.

Results of the power burst testing are discussed in further detail in Section 3.5.

\subsection{Power Bursts}

The power burst testing consisted of two power bursts during RIA-ST-1 and one power burst for each of RIA-ST-2, RIA-ST-3, and RIA-ST-4. The test rod energy deposition data for the five power bursts are summarized in Table VI. Fuel rod failure occurred in all of the phases except RIA-ST-3. A brief discussion of the power burst testing is given below.

3.5.1 RIA-ST-1 Power Bursts. A total pellet surface energy of $205 \mathrm{cal} / \mathrm{g} \mathrm{VO}_{2}$ at the axial flux peak was deposited during the first power burst. No indication of fuel rod failure was observed. As shown in Figure 6 , both of the 69 MPa EG\&G pressure transducers 10cated at the ends of the flow shroud indicated a series of small amplitude pressure disturbances probably caused by the sudden steam formation and water expulsion from the flow shroud following the power burst.

As illustrated by Figure 7 , the shroud inlet flow turbines ind $i$ cated a rapid flow increase at about the time of peak power. This 
TABLE VI

RIA SCOPING TEST SUMMARY

\begin{tabular}{|c|c|c|c|c|}
\hline $\begin{array}{l}\text { TRANSIENT } \\
\text { NUMBER }\end{array}$ & $\begin{array}{l}\text { REACTOR } \\
\text { PERIOD } \\
\text { (ms) }\end{array}$ & $\begin{array}{l}\text { TOTAL RADIALLY } \\
\text { AVERAGED ENERGY [a] } \\
\left(\text { CAL } / G\left(\mathrm{JO}_{2}\right)\right.\end{array}$ & $\begin{array}{l}\text { TOTAL PELLET } \\
\text { SURFACE ENERGY [a] } \\
\left(\mathrm{CAL} / \mathrm{G} \cup \mathrm{O}_{2}\right)\end{array}$ & $\begin{array}{l}\text { ROD } \\
\text { FAILURE }\end{array}$ \\
\hline $\begin{array}{l}\text { RIA-ST-] } \\
\text { PB-1 }\end{array}$ & 5.7 & 192 & 205 & NO \\
\hline $\begin{array}{l}\text { R IA-ST - ] } \\
P B-2\end{array}$ & 4.4 & 244 & $? 61$ & YES \\
\hline RIA-ST-? & 4.6 & 239 & 256 & YES \\
\hline RIA-ST-3 & 5.2 & 204 & 218 & NO \\
\hline RIA-ST-4 & 3.85 & 527 & 849 & YES \\
\hline $\begin{array}{l}\text { [a] Total } \\
\text { Fuel } r \\
\text { Fue } 1 r \\
\text { discre }\end{array}$ & $\begin{array}{l}\text { energy in } \\
\text { rod ener qy } \\
\text { rod energy } \\
\text { epancy is }\end{array}$ & $\begin{array}{l}\text { les } 15.3 \mathrm{cal} / \mathrm{g} \mathrm{UO}_{2} \\
\text { ues are based on the } \\
\text { ues based on SPND } \\
\text { ussed in Section } 4 \text {. }\end{array}$ & $\begin{array}{l}\text { ambient temperature } \\
\text { core ionization chan } \\
\text { out are ahout } 25 \% \text { h }\end{array}$ & $\begin{array}{l}\text { of } 538 \mathrm{~K} . \\
\text { er data. } \\
\text { her. This }\end{array}$ \\
\hline
\end{tabular}




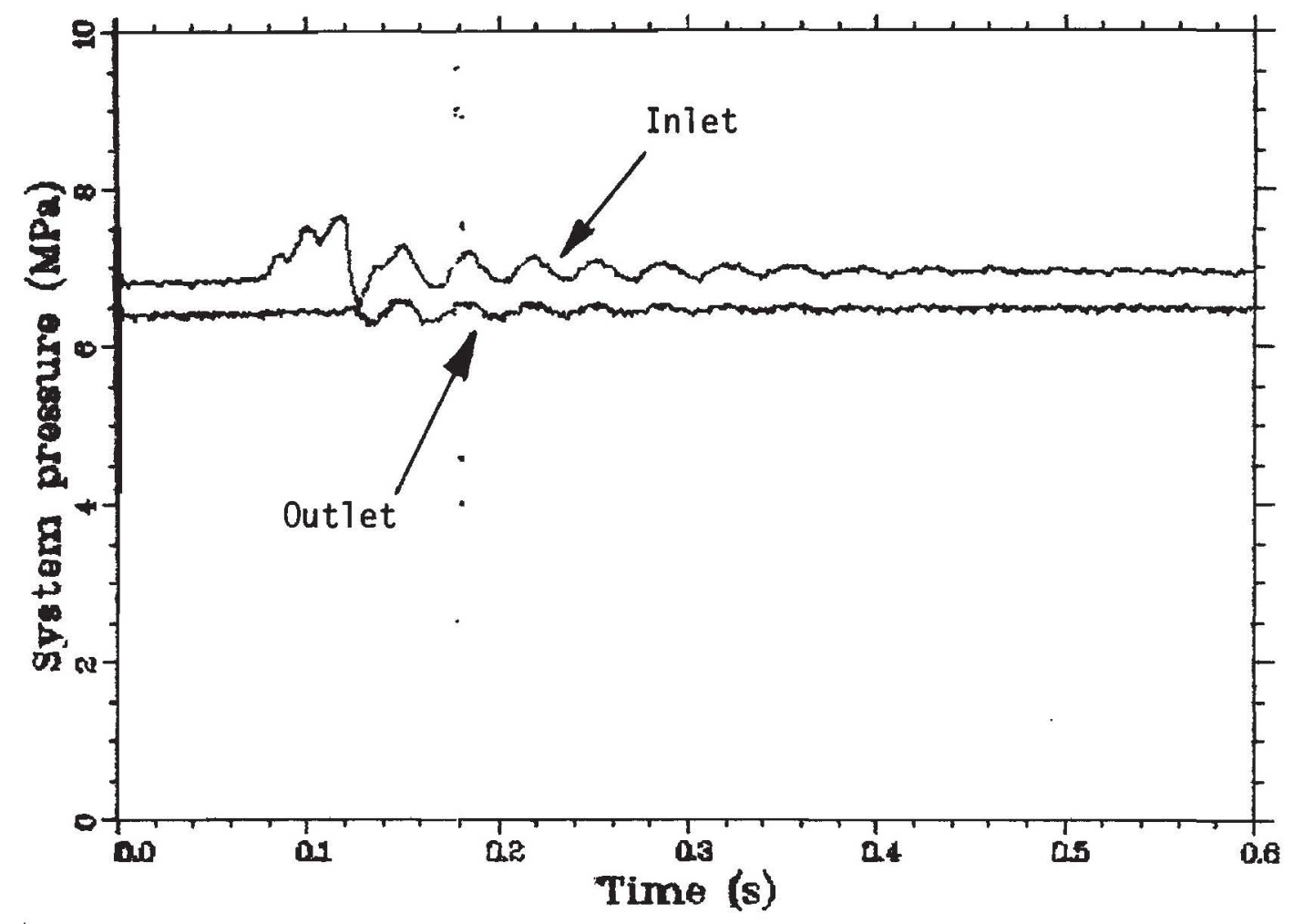

r!g.6 Coolant pressure vs. time at the flow shroud inlet and outlet during the first power burst of RIA-ST-1 as indicated by the $69 \mathrm{MPa}$ EG\&G pressure transducers.

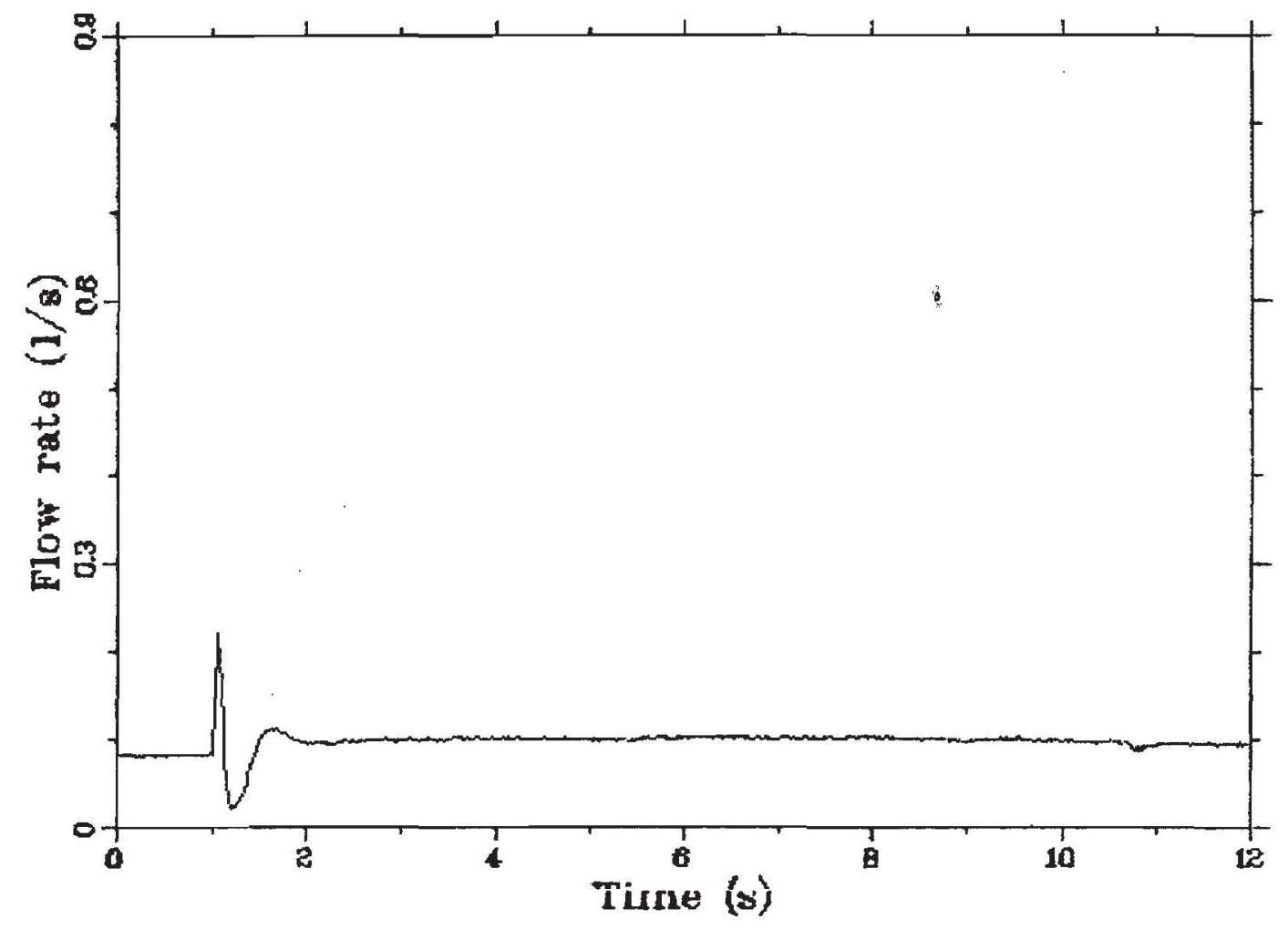

Fig.7 Shroud coolant flowrate at the inlet Auntun tho first nowar burst of RIA-ST-1. 
indicated flow increase, observed in all five power bursts, is believed to be incorrect and due to radiation sensitivity of the flow turbine pick-up coil or signal conditioning electronics. More will be said about this problem in Section 4.4 .

The second power burst of RIA-ST-1, performed on the same rod used in the first burst, deposited a total pellet surface energy of $261 \mathrm{cal} / \mathrm{g} \mathrm{UO}_{2}$ at the axial flux peak. The first indication of fuel rod failure was from a plant radiation monitor located near the test loop piping in the basement of the reactor building. Approximately six minutes following the power burst, rod failure was indicated by a sharp increase in the radiation field. Rod failure was also indicated about $1.5 \mathrm{mi}$ nutes later by the fission product detection system. None of the pressure transducers or other test train instruments indicated the time of rod failure. The exact time of fuel rod failure is uncertain due to the long time necessary for coolant to flow from the fuel rod to the radiation monitor locations.

\subsubsection{RIA-ST-2 Power Burst. The RIA-ST-2 fuel rod was exposed} to a single power burst with no significant steady state operation. The pellet surface energy of $256 \mathrm{cal} / \mathrm{g} \mathrm{U0} \mathrm{O}_{2}$ deposited during the single power burst resulted in fuel rod failure. The loop monitor indicated failure about 7 minutes and the fission product detection system about 7.5 minutes after the power burst. None of the test train instrumentation indicated fue 1 rod failure.

\subsubsection{RIA-ST-3 Power Burst. The RIA-ST-3 fuel rod was subjected} to a single power burst which deposited a pellet surface energy of $218 \mathrm{cal} / \mathrm{g} \mathrm{UO}_{2}$ at the axial flux peak. Neither the loop monitor or the fission product detector indicated fuel rod failure.

\subsubsection{RIA-ST-4 Power Burst. After the power calibration was} completed for RIA-ST-4, the fuel rod was subjected to a single power burst which deposited $527 \mathrm{cal} / \mathrm{g} \mathrm{UO} \mathrm{O}_{2}$ radially averaged at the axial flux peak or $849 \mathrm{cal} / \mathrm{g}$ at the fuel pellet surface. As expected, this large energy deposition resulted in immediate fuel rod failure. A 
1 arge pressure pulse was recorded by the lower $69 \mathrm{MPa}$ EG\&G pressure transducer connected to the lower end of the flow shroud. The Bell and Howell pressure transducer, connected via small diameter tubing to the flow shroud at the axial flux peak elevation, indicated a pressure pulse which exceeded the $17 \mathrm{MPa}$ rating of the transducer. The time of the pressure increase was about $4 \mathrm{~ms}$ after the time of peak power. The fuel rod total energy, radially averaged at axial flux peak, was $280 \mathrm{cal} / \mathrm{g} \mathrm{UO} \mathrm{O}_{2}$ at the time of rod failure. This corresponds to a fuel surface energy of $447 \mathrm{cal} / \mathrm{g}$. Further discussion of the pressure pulse detected during RIA-ST-4 can be found in Section 4.3 .

The fission product detection system indicated rod failure about 3.25 minutes after the power burst. The loop radiation monitor indicated rod failure within two minutes after the power burst. Data from the fission product detection system are discussed in detail in Section 6 . 


\section{TEST RESULTS}

Test results presented herein correspond to one of the four questions (Section 1) which made up the objective of the RIA Scoping Test. Where applicable, the results of pretest predictions are included to compare with the test data.

\subsection{Applicability of Calorimetric Measurements to Power Burst Testing}

The first objective of the RIA Scoping Test was to evaluate the applicability of extrapolating low-power calorimetric measurements to determine fuel rod energy depositions during a power burst. Radiochemical analysis to directly measure the power burst fuel rod energy deposition in the RIA Series 1 program tests will not be possible due to extensive operation for preconditioning the fuel rods before the power burst.

Relating the calorimetric power calibration results of the RIA Scoping Test to the response of each of four core neutron detecting chambers was used to measure the fuel rod energy deposition during each power burst.

Reactor physics calculations were made of the test rod and PBF core rod values of energy per fission during steady state and transient operation. These calculated values were used to convert test rod power per core power during steady state operation to cal/g $\mathrm{UO}_{2}$ per core energy release during a power burst. The output of the core neutron detecting chambers during each power burst was integrated to yield the total core energy release. The core energy release was multiplied by the test rod energy deposition per core energy release ratio in terms of $\mathrm{cal} / \mathrm{g} \mathrm{UO}_{2}$ per $\mathrm{MJ}$.

A similar procedure was also used to measure fuel rod energy deposition by relating the calorimetric power calibration results to the three SPNDS. The output of each SPND was integrated during a power burst. The integrated detector output was multiplied by the 
cal $/ 9 U_{2}$ per SPND output current'seconds which was determined from the steady state power calibration data. The fuel rod energy values determined from the four core neutron chambers and the three SPNDs are given in Table VII. Data from the EV-2 core ionization chamber were not included in the preliminary estimates of fuel rod energy for each power burst since this ionization chamber consistently indicated higher powers and core energies than the other three ionization chambers. It appears that the chamber intercalibration constants were incorrect for EV-2.

Note in Table VII that the fuel rod energy values as determined from the three SPNDs are about 25\% higher than those obtained from the core ionization chambers. The cause of this discrepancy is not known, but some possible reasons are:

(1) The axial power profile in the IPT for a power burst may be different than the profile during steady state operation. The $0.229 \mathrm{~m}$ and the $0.686 \mathrm{~m}$ SPNDs indicate fuel rod energies about $15 \%$ higher than the $0.457 \mathrm{~m}$ SPND. Scan measurements of the cobalt flux wires attached to the outer surface of the flow shrouds have not been completed to date, but will provide profile information prior to the RIA Series 1 tests. Data from the SPNDs indicate only slight differences in the steady state and transient power profiles.

(2) The time response of the SPNDs and associated electronics may not be adequate to follow a rapid power burst. A comparison of the PBF core power during RIA-ST-3 as derived from the $0.229 \mathrm{~m}$ SPND and the TR-1 core ionization chamber is shown in Figure 8 . The power-time curve shapes for the two detectors are similar, but the SPND indicates higher power during the entire power burst. The similarity of the two curves implies that the SPND and associated electronics time response characteristics are not the problem. 
TABLE VII

SUMMARY OF FUEL RON FNERGY TATA [a]

\begin{tabular}{|c|c|c|c|c|c|c|c|c|c|c|}
\hline $\begin{array}{l}\text { Test } \\
\text { Designationn }\end{array}$ & $\begin{array}{l}\text { Fup } 1 \text { Rod } \\
\text { Energy } \\
\text { From } \\
\text { Core rhamher } \\
\text { TR-1 } \\
\left.\text { (Cal/g } 10_{2}\right)\end{array}$ & $\begin{array}{l}\text { Fuel Rod } \\
\text { Ener ov } \\
\text { From } \\
\text { Core Chamber } \\
\text { TR-2 } \\
\left(\mathrm{Ca} 1 / \mathrm{g} \quad \mathrm{NO}_{2}\right)\end{array}$ & 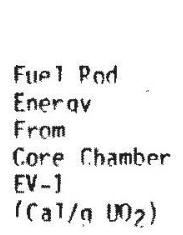 & $\begin{array}{l}\text { Fuel find } \\
\text { Eneray } \\
\text { Fron } \\
\text { Conre Chamher } \\
\text { EV-? } \\
\text { (C.al/a Un?) }\end{array}$ & 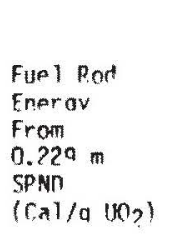 & 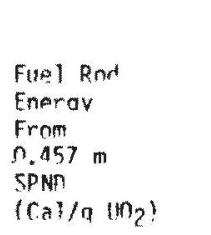 & $\begin{array}{l}\text { Fuel Rnd } \\
\text { Enoroy } \\
\text { Frnm } \\
\text { O..RR m } \\
\text { SPRn } \\
\text { Iralla Unol }\end{array}$ & $\begin{array}{l}\text { Fuel Pand } \\
\text { Enerav } \\
\text { Frrm } \\
\text { TR-1, TR-7. } \\
\text { and EV-1 } \\
\text { Cnre } \\
\text { Chamher } \\
\text { 'ral/a un? }\end{array}$ & $\begin{array}{l}\text { Funl Pnd } \\
\text { Enerav } \\
\text { From } \\
\text { Threas } \\
\text { SPNR } \\
\text { Iralla ungs }\end{array}$ & $\begin{array}{l}\text { Difference } \\
\text { in Fuel } \\
\text { Ror Enerav } \\
\text { Yalues for } \\
\text { rore Chamhers } \\
\text { and SPMOs } \\
\text { (Parcent) }\end{array}$ \\
\hline $\begin{array}{l}\text { RIA-ST-1 } \\
\text { Power Burst-1 }\end{array}$ & 195 & 191 & 188 & 211 & $26 \mathrm{~F}$ & $2 ? ?$ & 251 & $19 ?$ & $3 A ?$ & $? 1$ \\
\hline $\begin{array}{l}\text { RIA-ST-? } \\
\text { Power Burst -? }\end{array}$ & 785 & 24,7 & 744 & 270 & 34.3 & 304 & 338 & $3 \sqrt[4]{4}$ & 325 & 25 \\
\hline RIA-ST - ? & 241 & 735 & 240 & 259 & 318 & $2 n 1$ & 3.30 & 730 & 373 & $26^{\circ}$ \\
\hline RIA-ST -3 & 207 & $2 n 5$ & 304 & 208 & 287 & $26 ?$ & $27 \%$ & 204 & 375 & 26 \\
\hline R]A-ST -4 & 523 & Data Prohlem & 5.31 & 571 & 617 & Data Prohlem & h11 & a.?7 & 514 & 14 \\
\hline
\end{tabular}




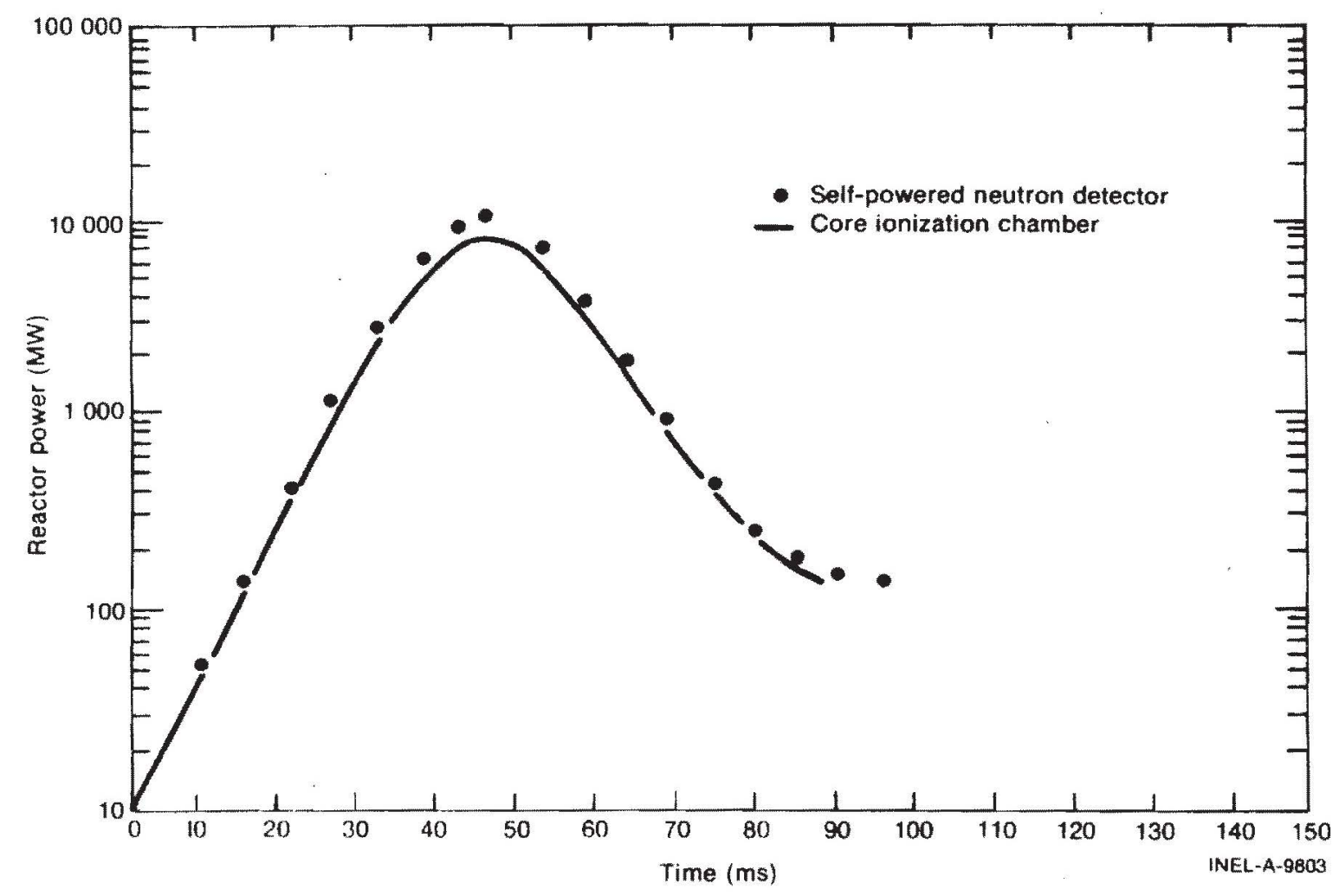

Fig.8 Corirarison of PBF core power during RIA-ST-3 as derived from $0.2 ?$ a SPII and TR-T core ionization chanber. 
(3) The steady state calibration of the SPNDs in terms of SPND current output per test rod power may not be correct for power burst testing. The SPND data was multiplied by the ratio of test rod energy per fission during a power burst to test rod energy per fission during steady state operation, name ly

\section{$\frac{172.2 \mathrm{MeV} / \text { fission }}{183.8 \mathrm{MeV} / \text { fission }}$}

The preliminary fuel rod energy values given in this report were determined from the core ionization chambers. These values were chosen in preference to the SPND derived data because the core chamber data was in excellent agreement with reactor physics calculations. Reactor physics pretest calculations performed by the EG\&G Reactor Physics Engineering Branch using a one-dimensional neutron-transport code predicted a test rod power per core power for RIA-ST-1 of $2.15 \mathrm{~kW} / \mathrm{m} / \mathrm{MW}$ versus 2.2 measured. A reactor physics calculation was not made for the RIA-ST-4 fuel rod since previous PCM Test Series power calibration results were available. In addition, if the SPND derived fuel rod energy data is used, then the fue 1 rod in RIA-ST-3 received a radially averaged energy of $275 \mathrm{cal} / \mathrm{g} \mathrm{U0_{2 }}$ or $296 \mathrm{cal} / \mathrm{g}$ $\mathrm{UO}_{2}$ at the pellet surface and yet did not fail. Fuel rod failure is predicted to occur at a pellet surface energy of $262 \mathrm{cal} / \mathrm{g} \mathrm{U0} 2$.

The actual fuel rod energy depositions for the RIA Scoping Test power bursts will not be determined for several months when the radiochemical analysis is completed. The accuracy of the procedures will be checked by radiochemical analysis of fuel samples from the fuel rods tested in RIA-ST-2 and RIA-ST-3. The irradiation history for these two rods was limited to single power bursts, so that the radiochemical analysis will represent only the transient energy deposition. 


\subsection{Failure Threshold}

Another objective of the RIA Scoping Test was determining the energy deposition failure threshold for the $5.8 \mathrm{wt} \%$ enriched fuel rods under commercial Boiling water Reactor hot startup conditions. The RIA Scoping Test Experiment Predictions Report ${ }^{[2]}$ identified the threshold as $262 \mathrm{cal} / \mathrm{g}$ deposited at the fuel pellet surface. From the results of the RIA-ST-1, RIA-ST-2, and RIA-ST-3 experiments (refer to Table VI) the failure threshold can be assumed to be between $218 \mathrm{cal} / \mathrm{g}$ where the fuel rod did not fail (RIA-ST-3) and $256 \mathrm{cal} / \mathrm{g}$ where the rod did fail (RIA-ST-2), using the energy depositions determined from the output of the core ionization chambers. The prediction is slightly above this range but in general agreement.

Presented in Section 5 are photographs taken of the fuel rods of RIA-ST-2 and RIA-ST-3, respectively. The severity of failure of the RIA-ST-2 rod and the appearance of the RIA-ST-3 rod indicates that the failure threshold is probably close to midway between the energy depositions of the RIA-ST-2 and RIA-ST-3 experiments. For Test RIA 1-1, therefore, it can be assumed, based on the photographs and supported by the pretest prediction, that a fuel surface energy of approximately $240 \mathrm{cal} / \mathrm{g}$ will be sufficient to induce rod failure.

\subsection{Pressure Pulse Generation}

The primary reason for the investigation into pressure pulse generation produced by RIA-induced rod failure is concern for the integrity of the PBF in-pile tube (IPT). Prior to running the Series 1 tests, an evaluation of maximum possible pressure pulses was made. As will be seen in this section, the source pressure which resulted from the rod failure in RIA-ST-4 was significant, however the pressures at the wall of the IPT were quite low.

Rod failures occurred in the second burst of RIA-ST-1, in RIA-ST-2, and in RIA-ST-4. Figure 9 illustrates coolant pressure with respect to time at the shroud inlet and in the upper plenum of the IPT 


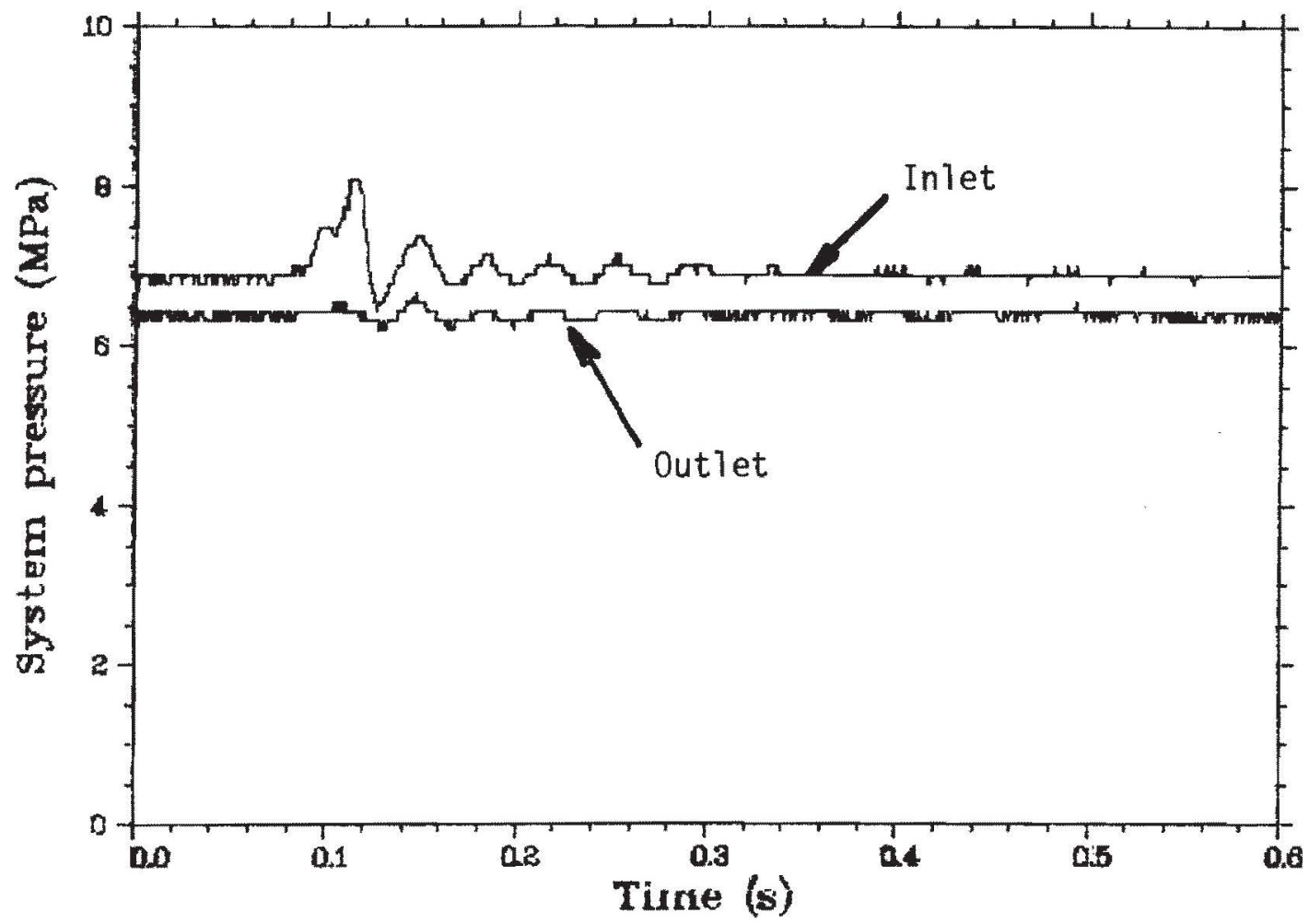

Fig. 9 Coolant pressure vs. time at flow shroud inlet and outlet during the second power burst of RIA-ST-1 as indicated by the 6.? MPa $\mathrm{EG} \& \mathrm{C}_{3}$ pressure transducers. 
subsequent to the second power burst of RIA-ST-1. The figure shows the same pressure oscillations seen in Figure 6 of Section 3.5.1. As pointed out in Section 3.5.1, the small amplitude pressure disturbances were probably caused by the sudden steam formation and water expulsion from the flow shroud due to the rapid heat transfer from the fuel rod following the power burst. It appears that at low energy depositions, there is no significant pressure pulse generation. This assumption is supported by the experiment predictions.

The rod failure of RIA-ST-4, however, was immediate and violent. For this test there were four pressure transducers capable of detecting the resulting pressure pulse as it was attenuated from the source to the walls of the in-pile tube. Figures 10 through 13 show the pressure history following the RIA-ST-4 power burst for each transducer. Referring to Figure 1 to determine approximate transducer location, it can be seen that the 17 MPa EG\&G pressure transducer (pressure trace in Figure 10) is outside the flow shroud near the top of the test rod. This transducer has the least direct view of the source pressure. Figure 10 indicates that a maximum pressure increase in the bypass region of $1.8 \mathrm{MPa}$ with a $4 \mathrm{~ms}$ rise time resulted from the source pressure.

The upper $69 \mathrm{MPa}$ EG\&G pressure transducer is attached to the hanger rod above the shroud outlet and beyond the upper particle filter. Figure 11, depicting the pressure history indicated by the upper $69 \mathrm{MPa}$ transducer, shows a pressure increase of $2.1 \mathrm{MPa}$ with a $3 \mathrm{~ms}$ rise time.

Figure 12 shows the pressure trace from the $17 \mathrm{MPa} \mathrm{Be} 11$ and Howell pressure transducer. This device was connected via a small diameter tube to the axial power peak location in the inside of the flow shroud. The Be11 \& Howell pressure transducer was most directly in view of the source pressure and would have given the best representation of it. However as shown by Figure 12, the pressure transducer saturated as a result of the source pressure pulse and did not provide the magnitude of the pressure pulse or a rise time. The transducer 


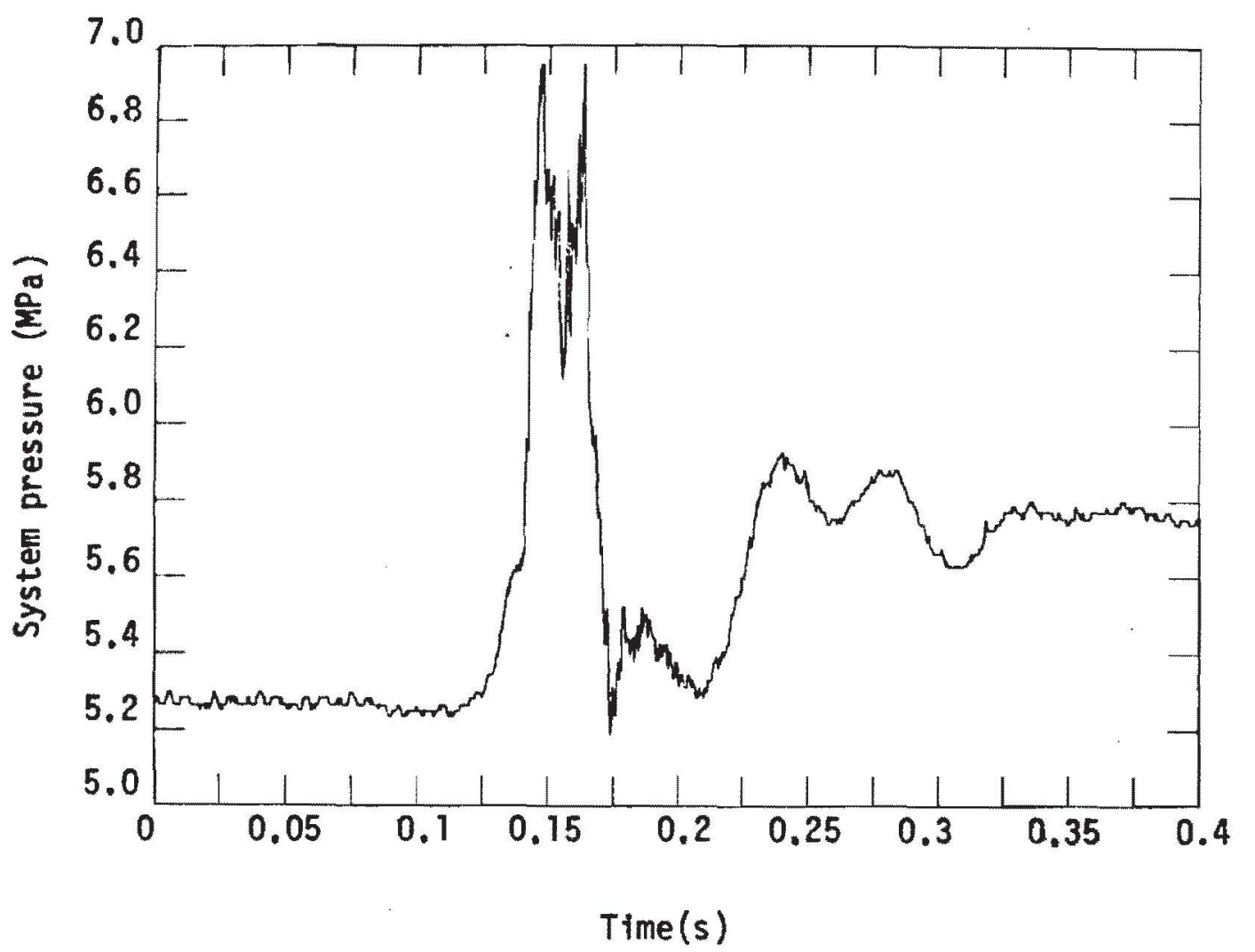

Fig. To Response of the $17 \mathrm{MPa}$ EG\&G pressure transducer during the power burst of RIS-ST -4 .

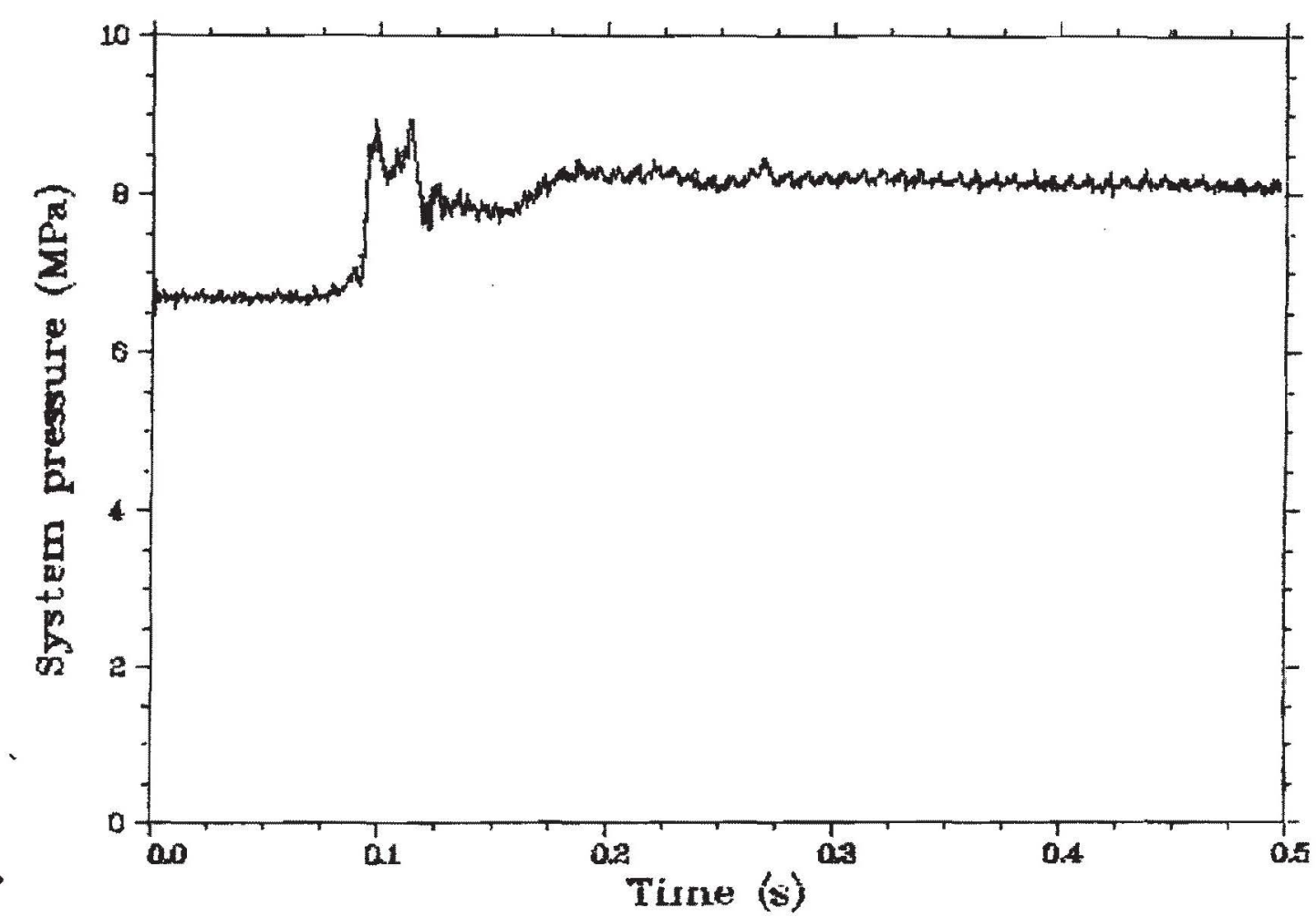

Fig.11 Response of the upper $69 \mathrm{MPa}$ EG\&G pressure transducer during the power burst of RIA-ST-1. 


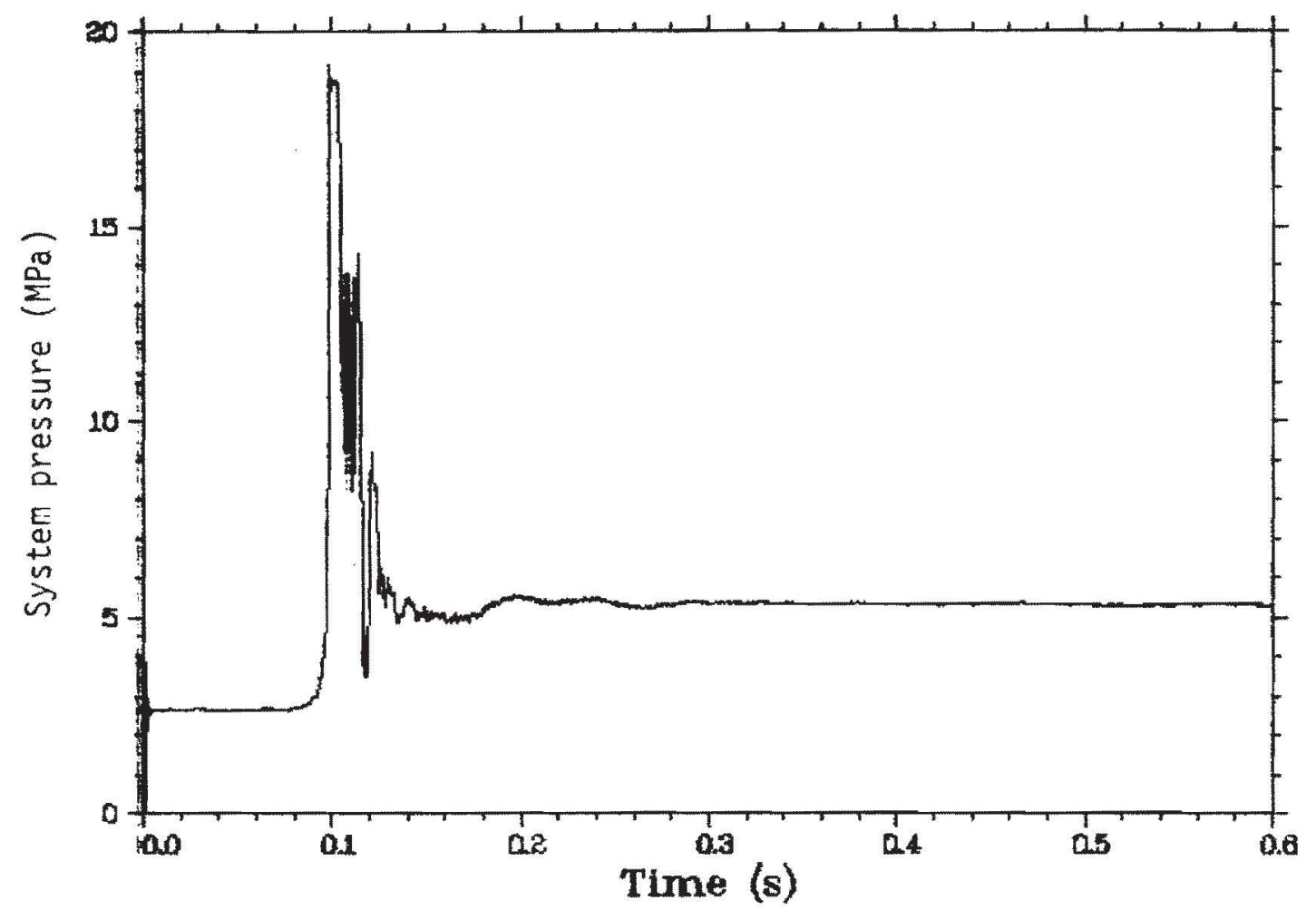

Fig. 12 Response of the $17 \mathrm{MPa}$ Bel1 \& Howe11 pressure transducer during the power burst of RIA-ST-4.

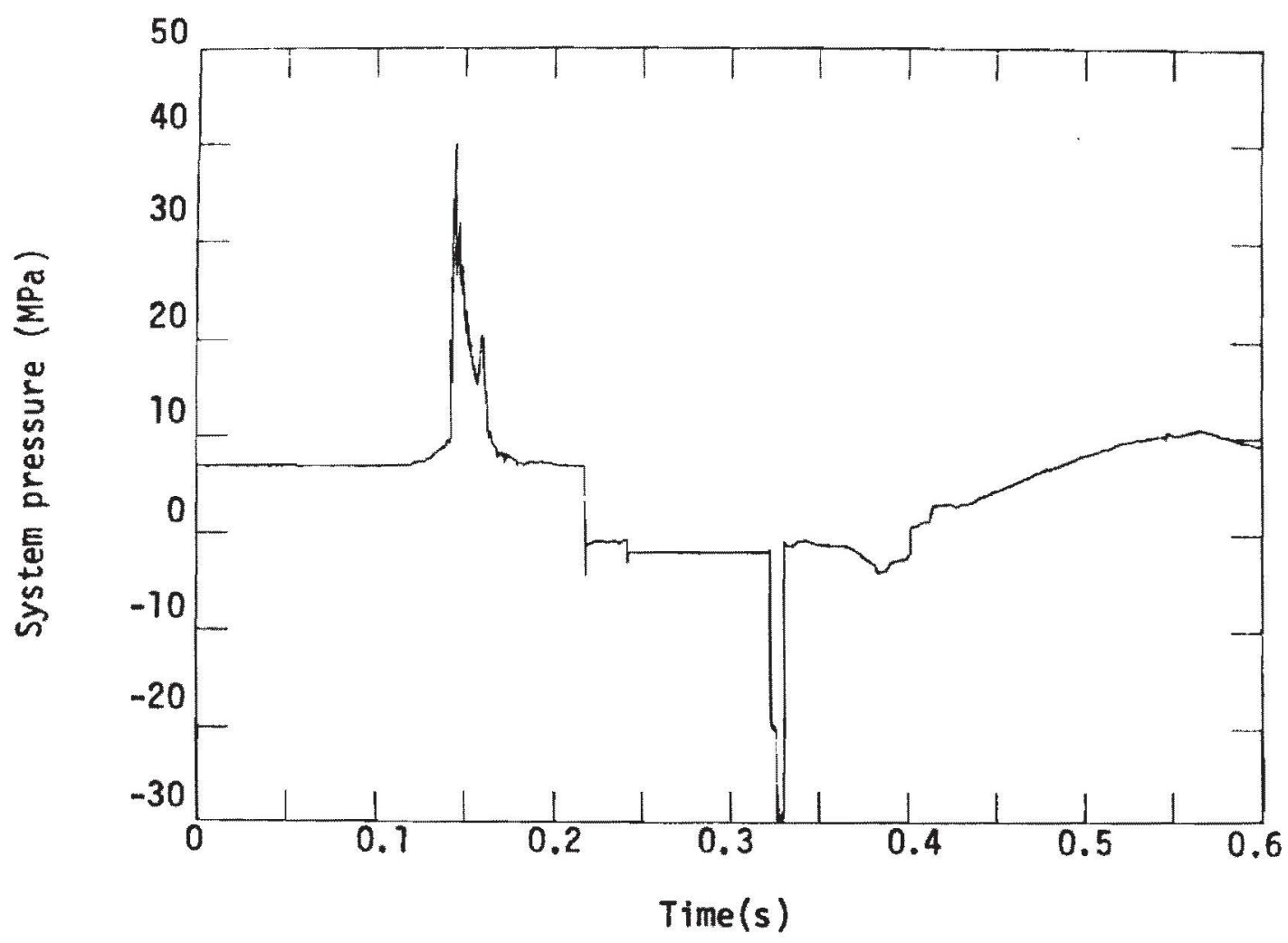

Fig. 13 Response of the lower $69 \mathrm{MPa}$ EG\&G pressure transducer during the power burst of RIA-ST-4. 
saturated at about $19 \mathrm{MPa}$ corresponding to a rise of about $16 \mathrm{MPa}$. The slope of the pressure rise was estimated to be approximately $20 \mathrm{MPa} / \mathrm{ms}$.

The $69 \mathrm{MPa}$ EG\&G pressure transducer was connected via a smal1 diameter tube into the inlet area of the flow shroud. The LVDT just above it was removed prior to RIA-ST-4, therefore this $69 \mathrm{MPa}$ pressure transducer was directly in-line with the source pressure pulse. Figure 13 shows the output of the $69 \mathrm{MPa}$ pressure transducer. The peak of the curve represents a pressure rise of $28.2 \mathrm{MPa}$ with a rise time of $1.6 \mathrm{~ms}$. The experiment predictions report for the Scoping Test indicated that a $475 \mathrm{cal} / \mathrm{g}$ energy deposition would result in a pressure pulse of $24.1 \mathrm{MPa}$ with pressure doubling of $31.7 \mathrm{MPa}$ at $7 \mathrm{~ms}$ after fuel dispersal.

Table VIII summarizes the pertinent data obtained from each of these transducers for RIA-ST-4. There were no significant pulses detected in the loop piping.

\subsection{Instrument Sensitivity}

The final objective of the RIA Scoping Test was to determine the sensitivity of the test instrumentation to high transient radiation exposures. This determination was essential for proper data evaluation in the RIA Series 1 tests. To facilitate the instrumentation evaluation, several environmentally isolated devices were added to the test train. The instruments intended specifically for instrument sensitivity evaluation during the RIA Scoping Test were as follows:

(1) One $17 \mathrm{MPa}$ Kaman, one $17 \mathrm{MPa}$ EG\&G, and one $69 \mathrm{MPa}$ EG\&G pressure transducer. The Kaman was located in the flow bypass region near the top of the test rod, while the EG\&G transducers were fixed to the hanger rod in the IPT upper plenum. All three pressure transducers were sealed to eliminate response due to coolant pressure changes. 
TABLE VIII

PRESSURE DATA FROM RIA-ST-4 POWER BURST

\begin{tabular}{|c|c|c|c|c|}
\hline $\begin{array}{l}\text { Pressure } \\
\text { Transducer }\end{array}$ & Location & $\begin{array}{l}\text { Pressure } \\
\text { Increase } \\
\end{array}$ & $\begin{array}{c}\text { Total Peak } \\
\text { Pressure } \\
\end{array}$ & $\begin{array}{l}\text { Rise }[\partial] \\
\text { Time }\end{array}$ \\
\hline $17 \mathrm{MPa} E G \& G$ & $\begin{array}{l}\text { Flow hypass } \\
\text { near top of } \\
\text { rod. }\end{array}$ & $\begin{array}{l}1.8 \mathrm{MPa} \\
(250 \mathrm{psi})\end{array}$ & $\begin{array}{l}8.5 \mathrm{MPa} \\
(1240 \mathrm{psi})\end{array}$ & $4 \mathrm{~ms}$ \\
\hline $69 \mathrm{MPa}$ EG\&G & $\begin{array}{l}\text { Upper plenum } \\
\text { heyond particle } \\
\text { screen. }\end{array}$ & $\begin{array}{l}2.1 \mathrm{MPa} \\
(310 \mathrm{psi})\end{array}$ & $\begin{array}{l}8.9 \mathrm{MPa} \\
(1280 \mathrm{psi})\end{array}$ & $3 \mathrm{~ms}$ \\
\hline $69 \mathrm{MPa}$ EG\& & Shroud inlet & $\begin{array}{l}28 . ? \mathrm{MPa} \\
(4100 \mathrm{psi})\end{array}$ & $\begin{array}{l}35.0 \mathrm{MPa} \\
(5080 \mathrm{psi})\end{array}$ & ]. $6 \mathrm{~ms}$ \\
\hline $17 \mathrm{MPa} B R_{k} H[b]$ & Source Region & $\begin{array}{l}15.9 \mathrm{MPa} \\
(2310 \mathrm{psi})\end{array}$ & $\begin{array}{l}27.7 \mathrm{MPa} \\
(3290 \mathrm{psi})\end{array}$ & $\begin{array}{l}20 \mathrm{MPa} / \mathrm{ms} \\
(2900 \mathrm{psi} / \mathrm{ms})\end{array}$ \\
\hline \multicolumn{5}{|c|}{$\begin{array}{l}\text { [a] Rise time is defined as the time from } 10 \% \text { to } 90 \% \text { of the pressure rise. } \\
\text { [b] Transducer saturated at a } \Delta P \text { of } 15.0 \mathrm{MPa}(2310 \mathrm{psi}) \text {. Rise time could } \\
\text { not be obtained but slope was approximate } 1 \mathrm{y} 20 \mathrm{MPa} / \mathrm{ms}(2900 \mathrm{psi} / \mathrm{ms}) \text {. }\end{array}$} \\
\hline
\end{tabular}


(2) One $17 \mathrm{MPa} \mathrm{Be} 11$ \& Howe 11 and one $17 \mathrm{MPa}$ Schaevitz pressure transducer. The Be11 \& Howe 11 transducer was connected via a tube to the source pressure region during RIA-ST-4. Both devices were fixed to the hanger rod. The $17 \mathrm{MPa}$ Schaevitz was inoperable.

(3) One Linear Variable Differential Transformer (LVDT) with the core locked in position. This LVDT was located in the flow bypass region at approximately the same elevation as the active LVDT.

(4) One Type $S$ thermocouple, located on the flow shroud at about the axial power peak elevation. This thermocouple was connected to the shroud for RIA-ST-1 only.

(5) Two strain gages, located on the flow shroud for radiation sensitivity evaluation. These were attached to the RIA-ST-1 flow shroud near the axial peak elevation.

Figure 14 illustrates the behavior of the blocked $69 \mathrm{MPa}$ EG\&G transducer. The device exhibited this behavior prior to and following each power burst of the Scoping Test with no visible change. It appears that the pressure transducer was defective. Figure 15 indicates the power burst behavior of the blocked $17 \mathrm{MPa}$ Kaman and EG\&G pressure transducers for the second burst of RIA-ST-1. This behavior was typical for all the bursts, varying in magnitude with the magnitude of the bursts. There was no significant difference in the indicated behavior with the occurence of fuel rod failure. Although the position of the Kaman transducer in the IPT subjected it to a higher neutron and gamma radiation than that experienced by the $17 \mathrm{MPa}$ EG\&G transducer, the pressure reponse of the Kaman showed less disturbance in all cases.

The Schaevitz pressure transducer was added to the test train because the LVDT-type device had not been previously used in PBF. For RIA-ST-1, the pressure transducer was connected via a small diameter 


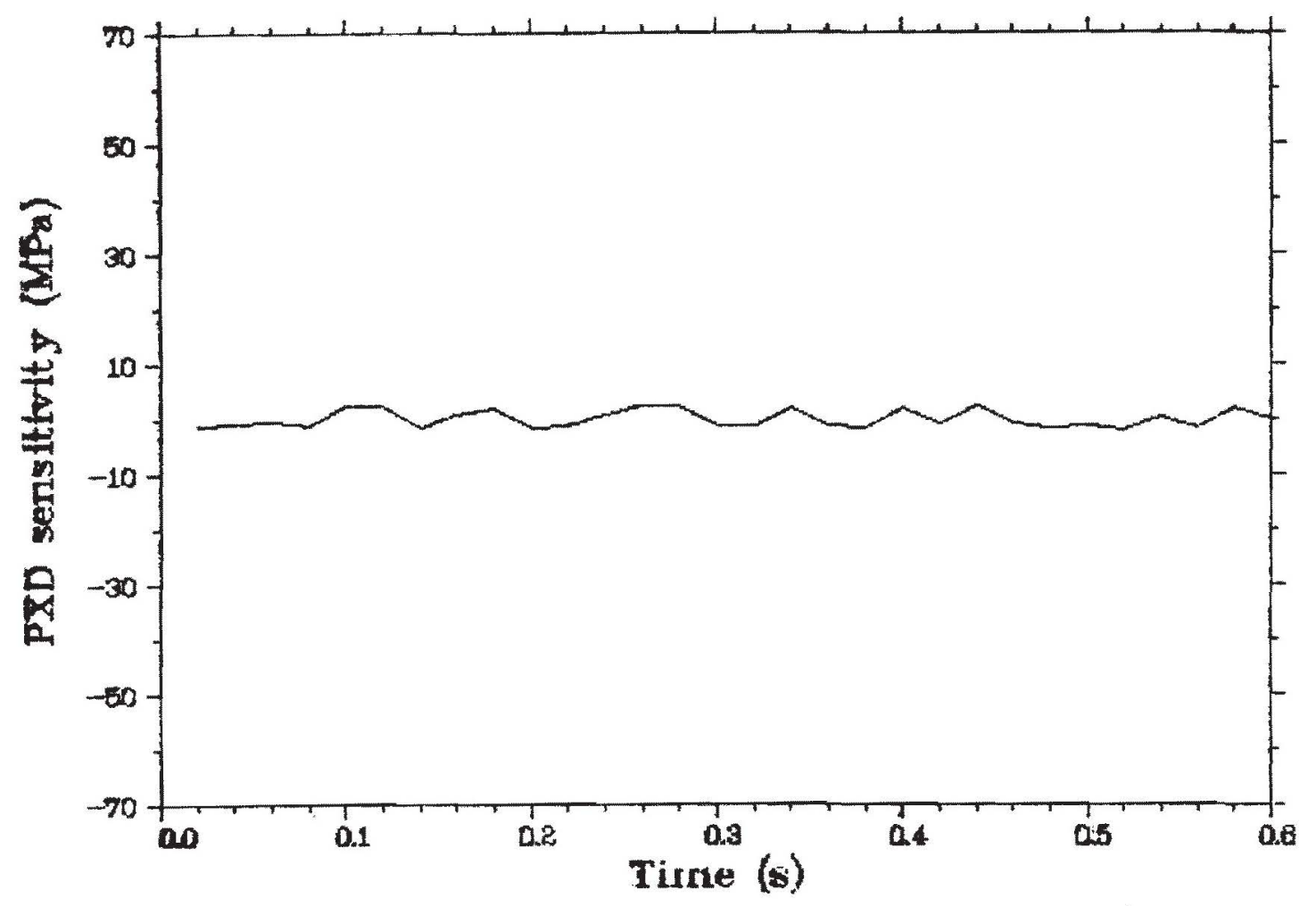

Fig. 14 Radiation sensitivity of the $69 \mathrm{MPa}$ EG\&G pressure transducer. (RIA-ST-4)

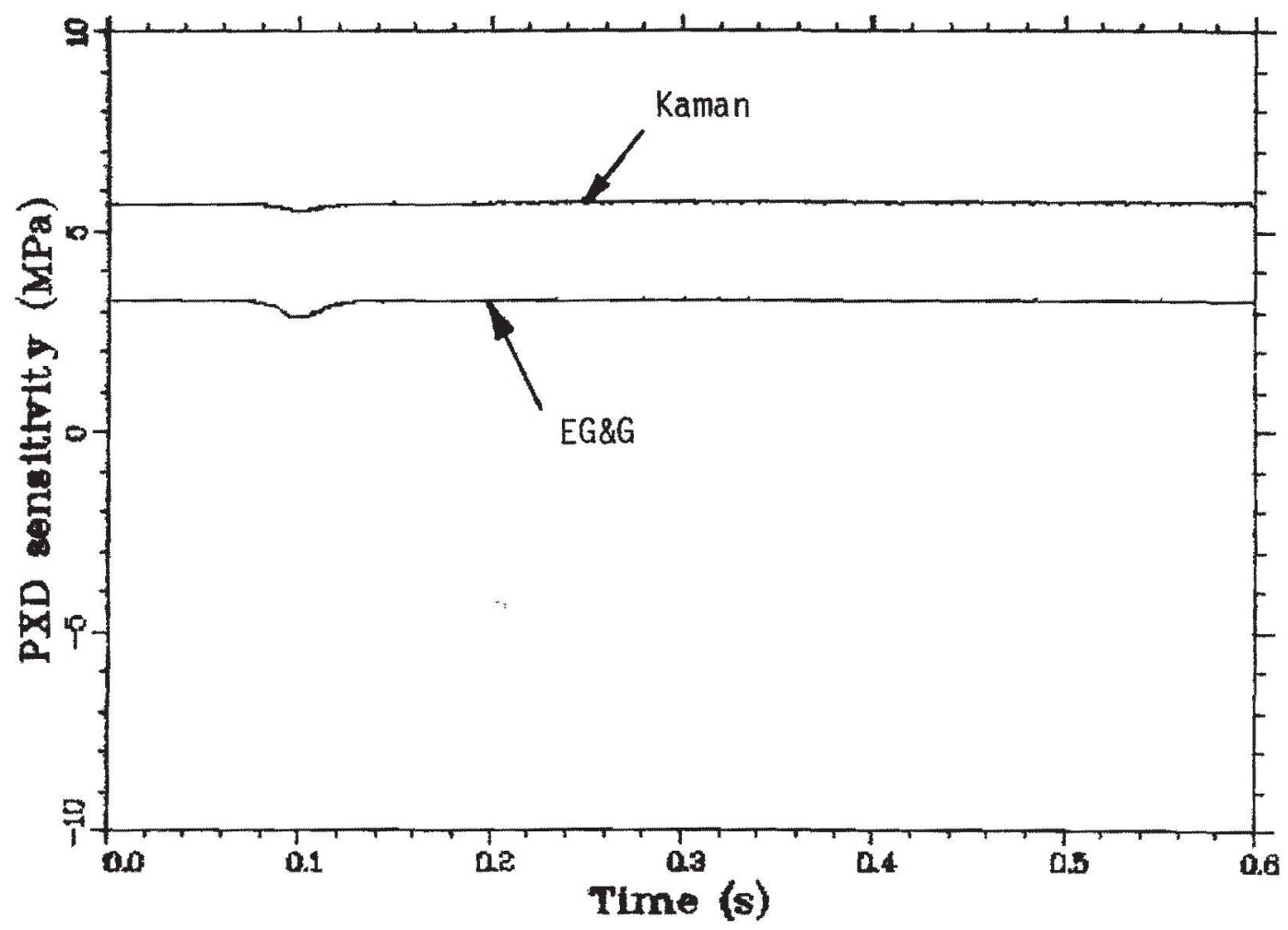

Fig. 15 Radiation sensittuity of the $17 \mathrm{MPa}$ EF\&G and Kaman pressure transducers. (RIA-ST-1, Burst 2) 
tube to the source pressure region inside the flow shroud. A damaged transducer lead resulted in water intrusion which rendered the device useless, therefore, no data was obtained to evaluate this device.

The $17 \mathrm{MPa}$ Be11 \& Howe 11 pressure transducer provided the pressure response indicated in Figure 16 to the power burst and subsequent rod failure of RIA-ST-1. There is no radiation sensitivity indicated. The transducer was connected via a small diameter tube to the source pressure region inside the flow shroud for RIA-ST-4. The pressure response for that phase was illustrated by Figure 12 in Section 4.3.

Figure 17 shows the response of the locked LVDT to the large power burst of RIA-ST-4. The trace shows no indication of radiation sensitivity. That was typical during all the power bursts.

During RIA-ST-1, a Type $S$ thermocouple and two strain gages were fixed to the outside of the flow shroud near the axial peak elevation. Figure 18 shows the response of the thermocouple to the power burst and subsequent rod failure. This trace is nearly identical to that for the first burst of RIA-ST-1 where there was no fuel rod failure. It can be presumed, therefore, that the slight increase in temperature indicated at $24 \mathrm{~s}$ on the curve is a result of radiation sensitivity (gamma heating) of the thermocouple. There was a more significant effect to the strain gages. Figure 19 illustrates the strain gage response to the second power burst of RIA-ST-1. Fuel rod failure does not contribute to this response as the strain gage trace for the first burst of RIA-ST-1 is similar, differing only in magnitude. The magnitude of strain gage response corresponds to the radiation intensity of each burst. In this case a $70 \%$ offset is induced which appears to be permanent.

Although a control device was not included in the Scoping Test, a significant problem was observed with the power burst response of the turbine flowmeters. Figure 20 illustrates the flowmeter response for RIA-ST-4. The rod failure during the RIA-ST-4 power burst occurred 


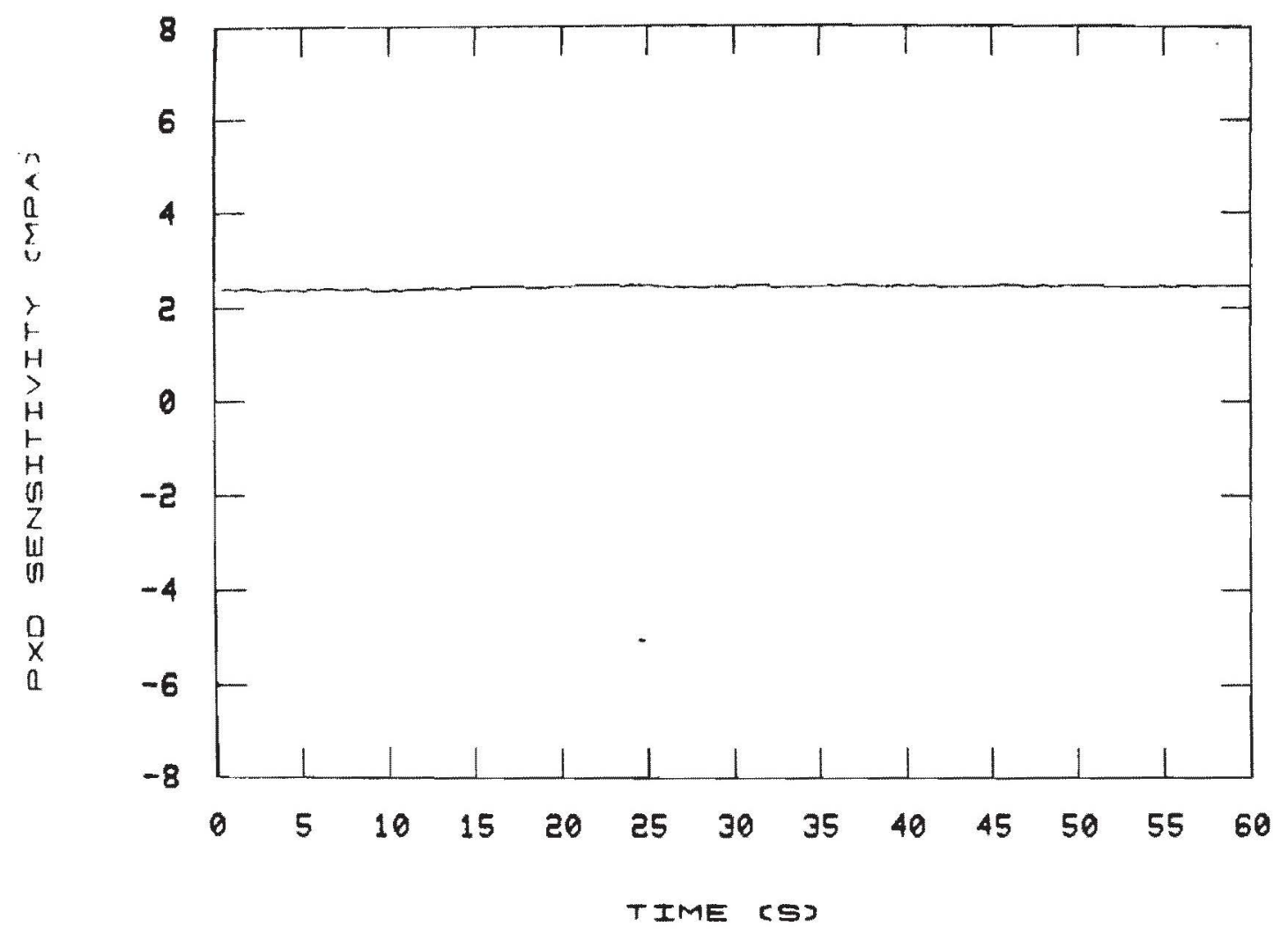

Fig. 16 Radiation sensitivity of the $17 \mathrm{MPa}$ Bell \& Howeil pressure transducer. (RIA-ST-1, Burst 2) 


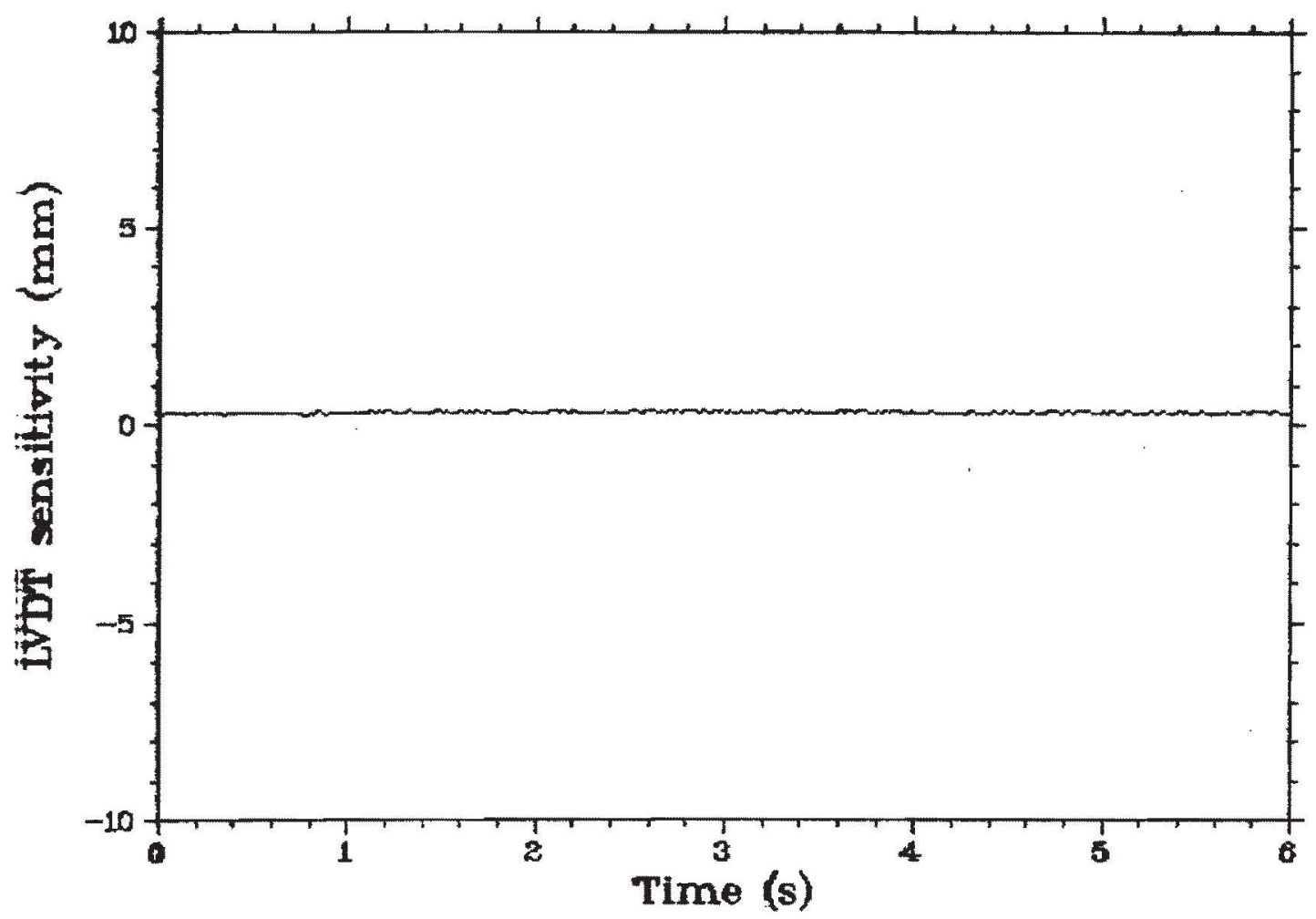

Fig. 17 Radiation sensitivity of the linear variable differential transformer. (RIA-ST-4)

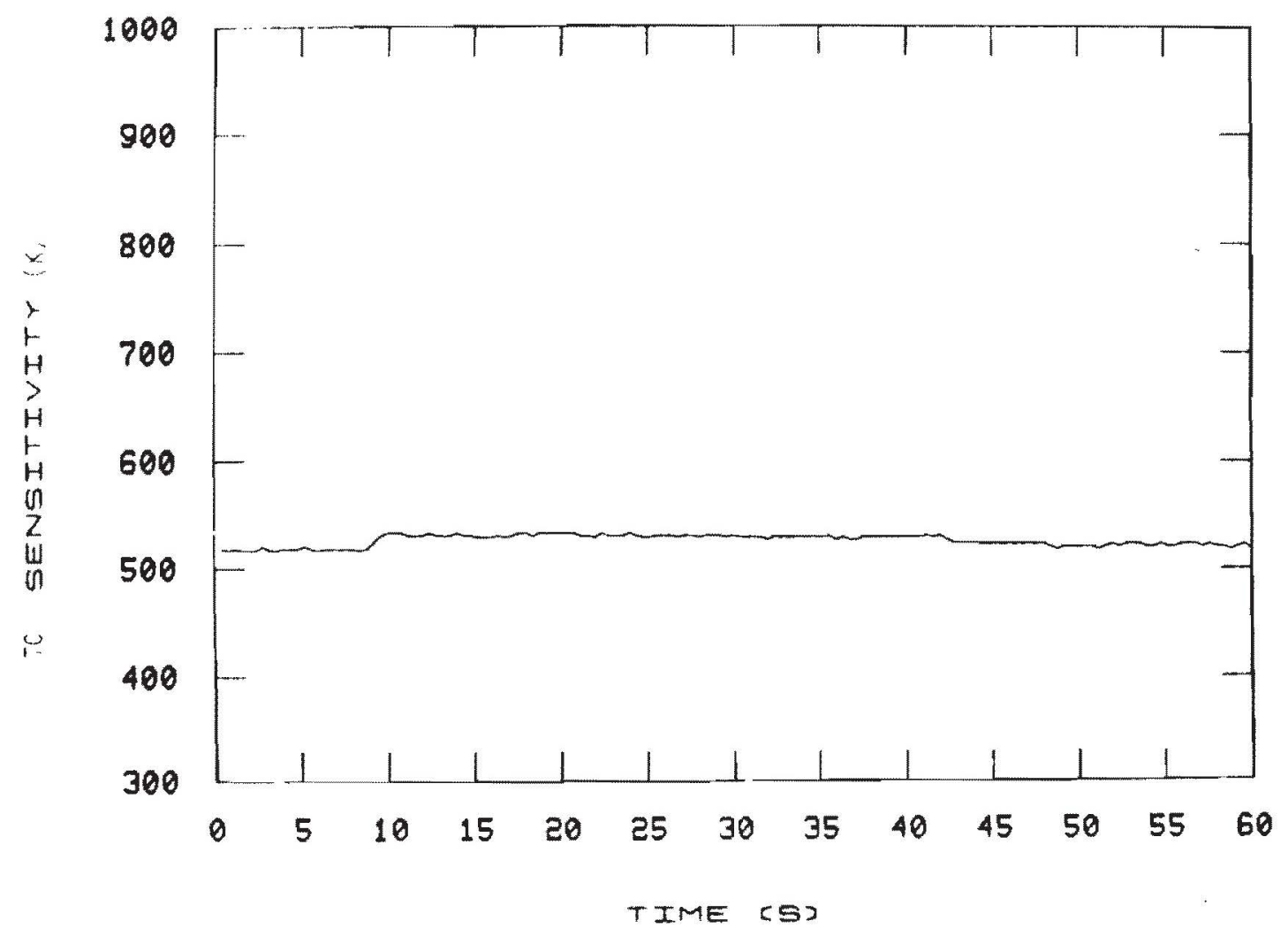

Fig. 18 Radiation sensitivity of the Type $S$ thermocouple. (RIA-ST-1, Burst 2) 


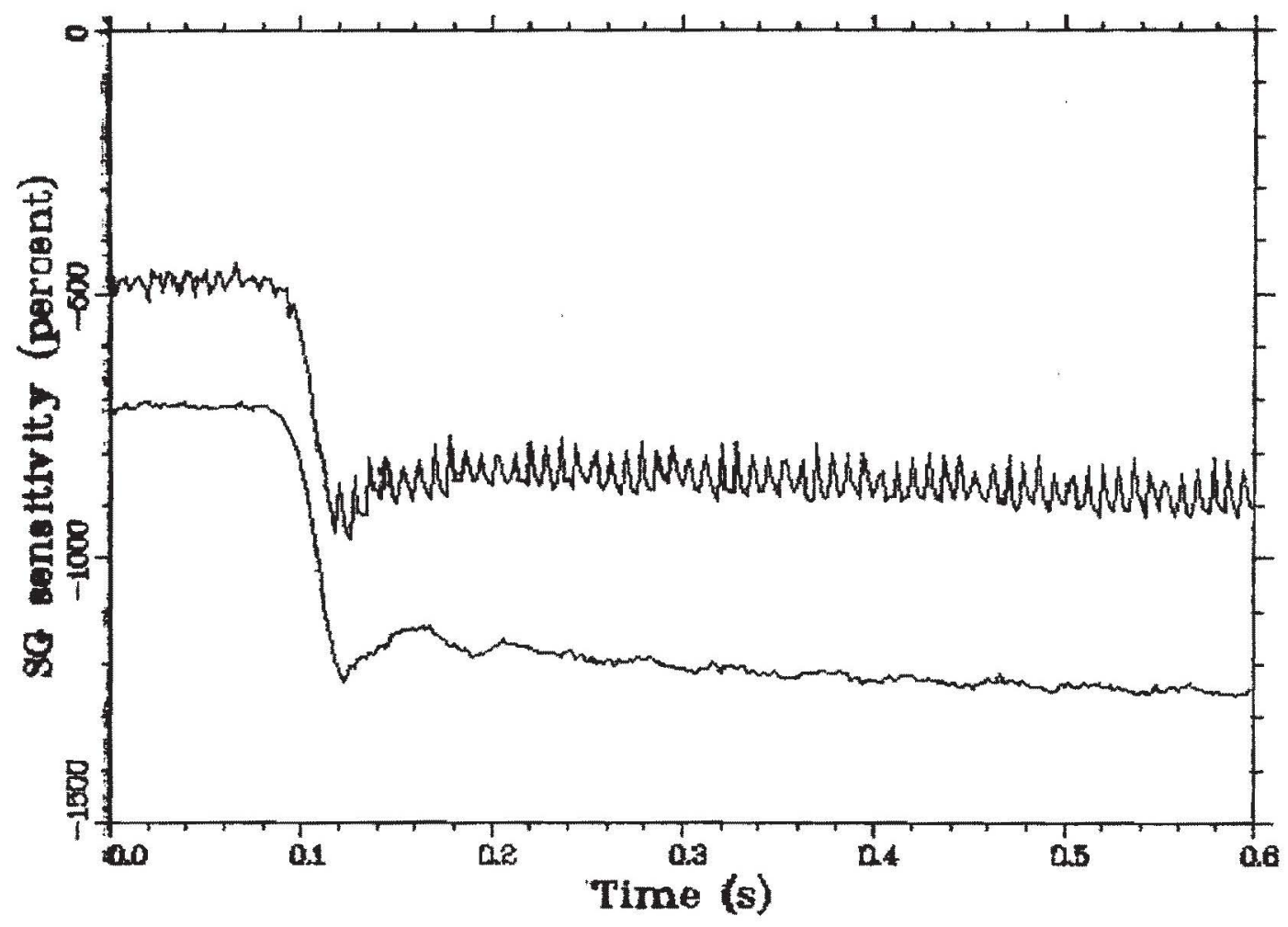

Fig. 19 Radiation sensitivity of the strain nanes. (PJ1-ST-1, Purst 2)

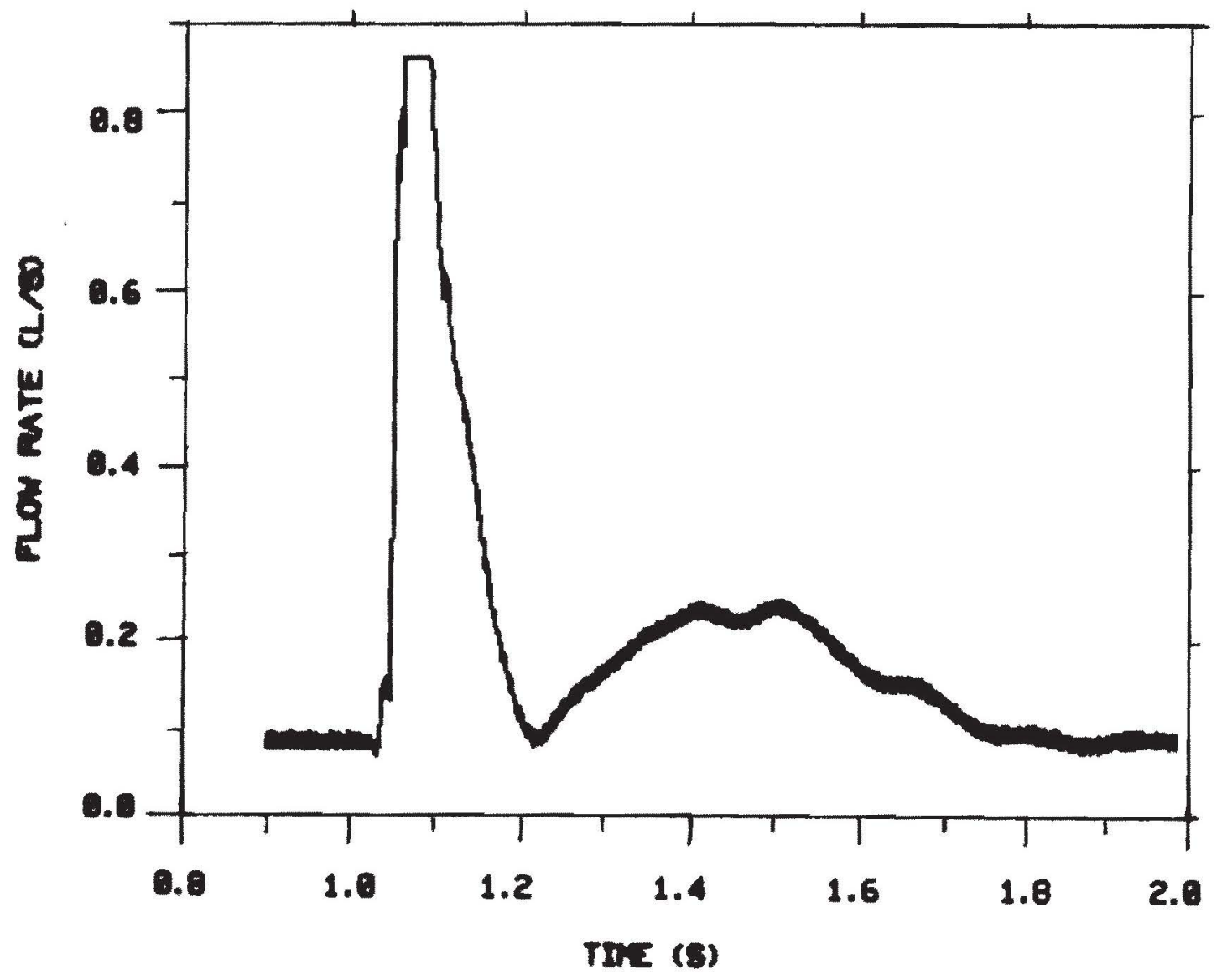

Fig. 20 Flowmeter response during the power burst and rod failure of RIA-ST-4. 
about $4 \mathrm{~ms}$ after the time of peak power. The failure was severe and caused significant coolant vaporization, subsequent flow shroud voiding, and probably flow reversal of the flow shroud inlet. The flowmeters are not bi-directional and will indicate positive flow even though it is negative, however, the flowmeter response should pass through zero anytime the flow changes direction. The flowmeter behavior indicated by Figure 20 is not as expected. There is no drop in flow following the rod failure. Instead, the indication is of a sharp increase in flow until the signal conditioning is saturated at $880 \mathrm{~cm}^{3} / \mathrm{s}$, followed by a decrease.

The pickup coils to a turbine flowmeter generate a sinusoidal current corresponding to the rotation of the turbine. This sinusoidal wave is converted to a flowrate indication by electronically counting the peaks on the wave. It is believed that the power burst adds a high frequency noise to the sinusoidal wave signal, thus causing the electronic counter to see many more peaks than can be attributed to the flow turbine rotation. This artificially high number of peaks translates to a much higher flow indication than there should be. 


\section{POSTTEST PHOTOGRAPHS}

Figures 21 through 26 illustrate the posttest condition of the rods from RIA-ST-2 and RIA-ST-3. The appearance of the rod from RIA-ST-1 was similar to that of the RIA-ST-2 rod.

Figure 21 shows the remnants of the fue 1 stack of the RIA-ST-2 rod between the 0.370 and $0.470 \mathrm{~m}$ rod elevations. Most of the fue 1 was gone, and only a small portion of the original fuel inventory in this region remained within the flow shroud. Preliminary examination indicates that the fuel in this region did not melt. A longitudinal slit in the cladding of this rod was observed between the 0.520 and $0.600 \mathrm{~m}$ rod elevations in the $0^{\circ}-180^{\circ}$ plane. A large percentage of the fuel was missing, as is shown in Figure 22. The cladding in this region is extremely brittle and may have experienced melting. Bulging of the cladding at the pellet interface (bambooing) was observed between the 0.675 and 0.780 rod elevations of the rod from RIA-ST-2 and is shown in Figure 23. Sma11, circumferentially oriented cracks occurred within the buige.

The flux peak region of the rod from RIA-ST-3 $(0.36$ to $0.450 \mathrm{~m})$ is shown in Figure 24. Severe oxidation and cladding deformation are evident. No breaks in the cladding were detected. Cladding waisting near the $0.60 \mathrm{~m}$ elevation of this rod is seen in Figure 25. The cladding in this portion of the rod has collapsed into pellet interfaces and pellet defects $(0.645 \mathrm{~m})$. Only two interfaces of the RIA-ST-3 rod exhibited bambooing. These occurred near $0.66 \mathrm{~m}$, and are shown in Figure 26. 


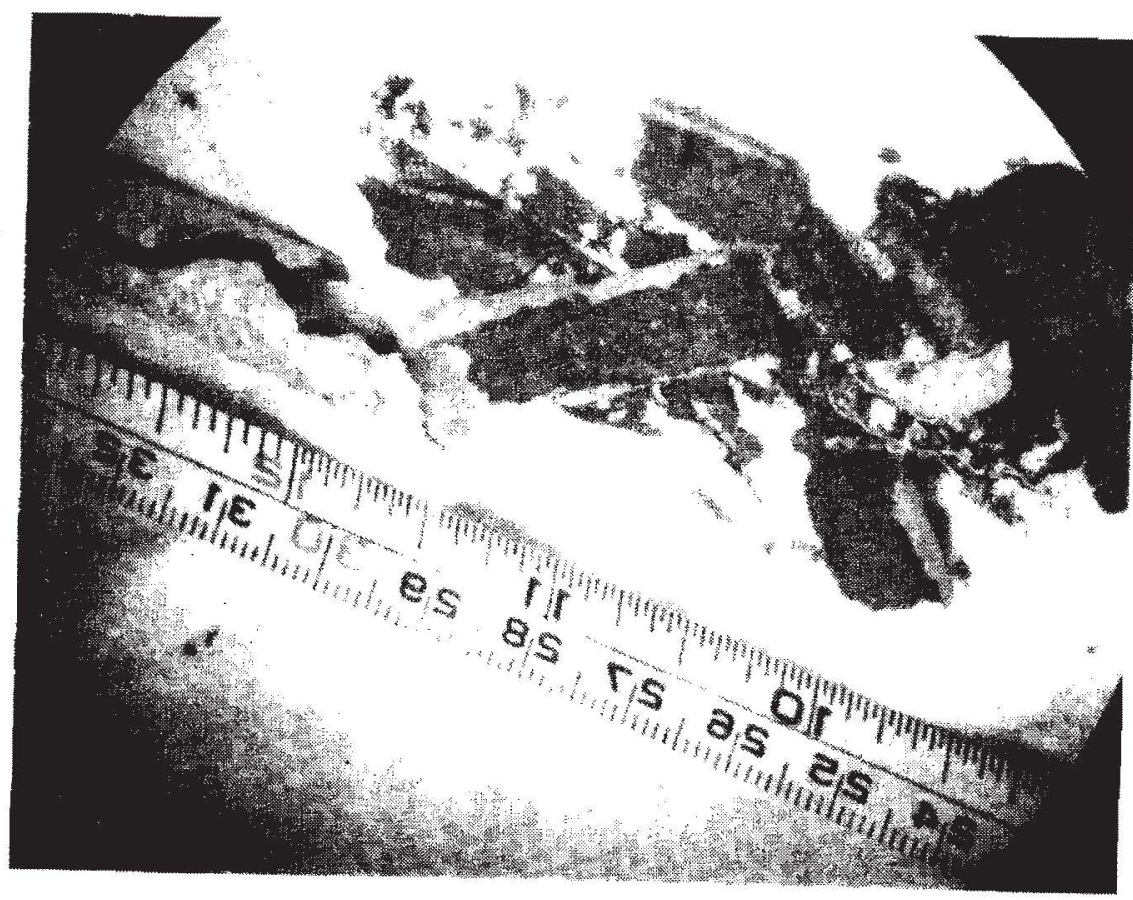

Fig. 21 Posttest photograph of fuel rod from RIA-ST-2 between 0.370 and $0.470 \mathrm{~m}$ rod elevations

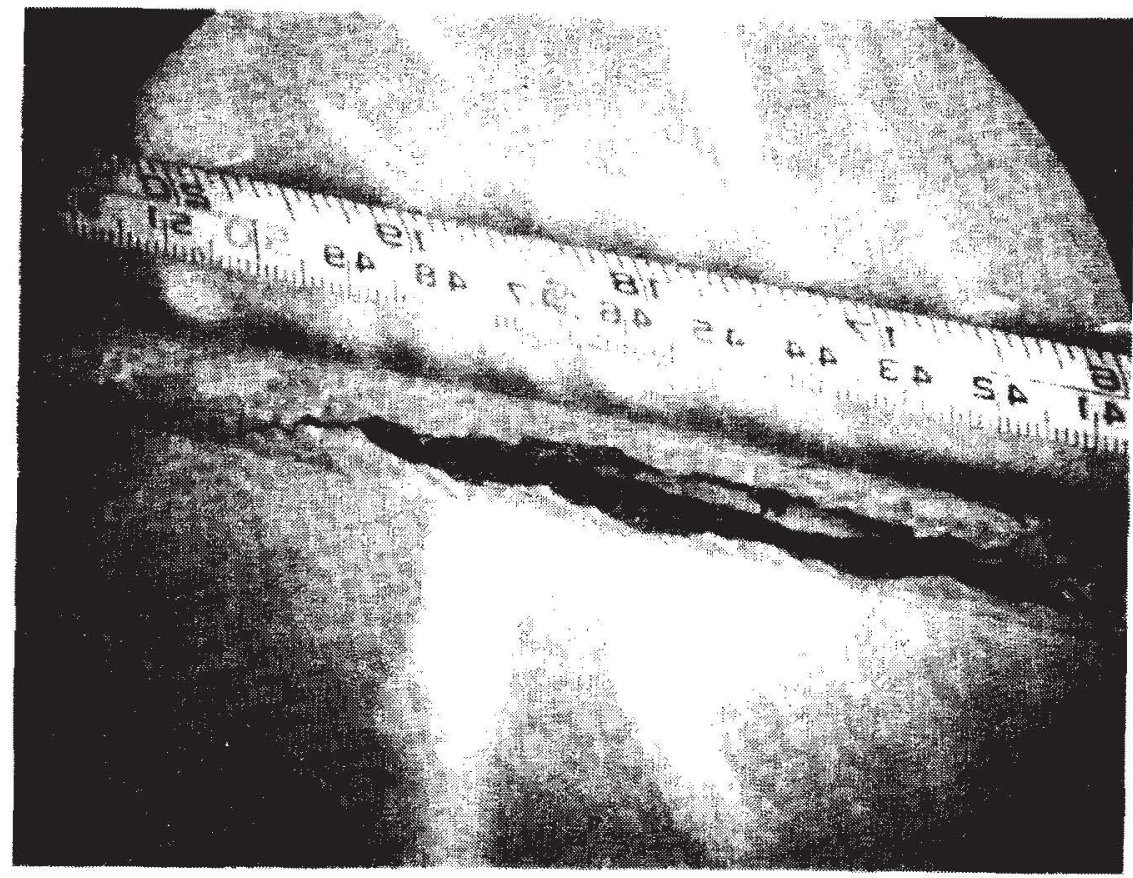

Fig. 22 Posttest photograph of fuel rod from RIA-ST-2 between
the 0,520 and $0,600 \mathrm{~m}$ rod elevations 


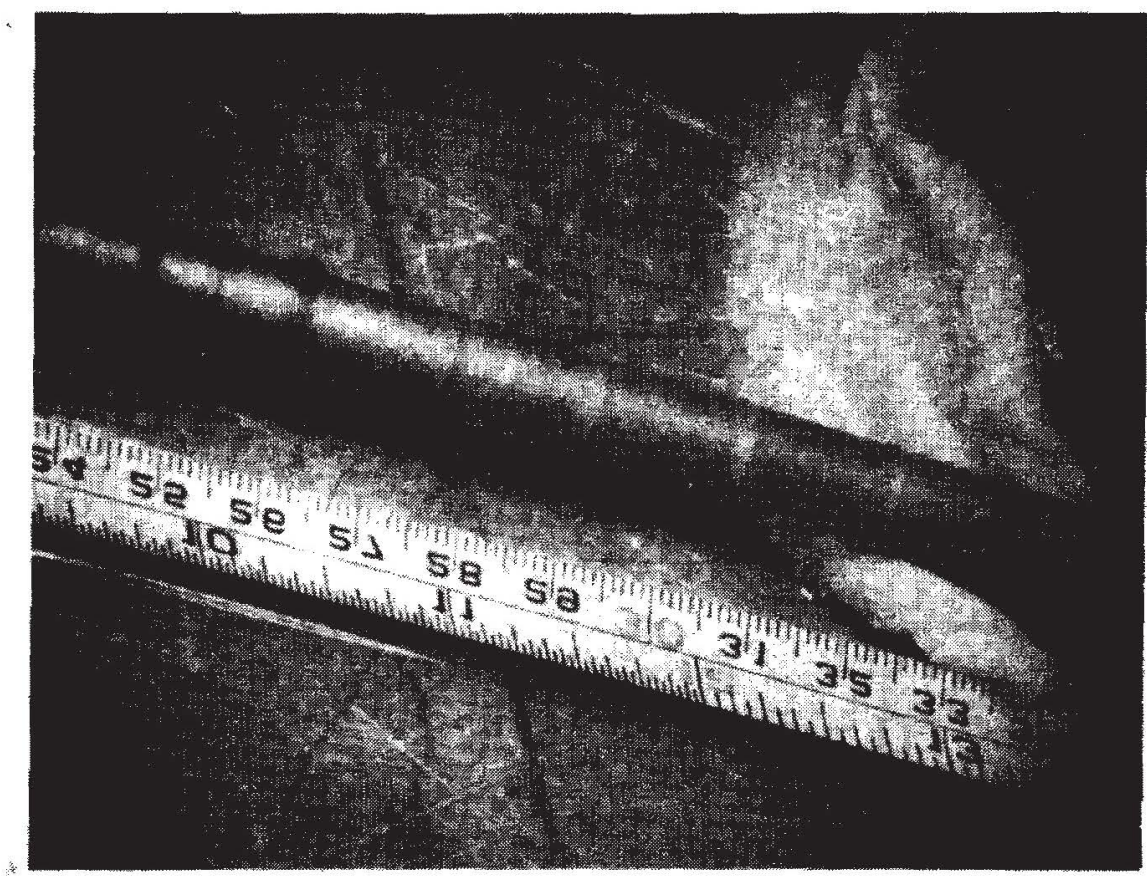

Fig. 23 Posttest photograph of fuel rod from RIA-ST-2 between the 0.675 and $0.780 \mathrm{~m}$ rod elevations 

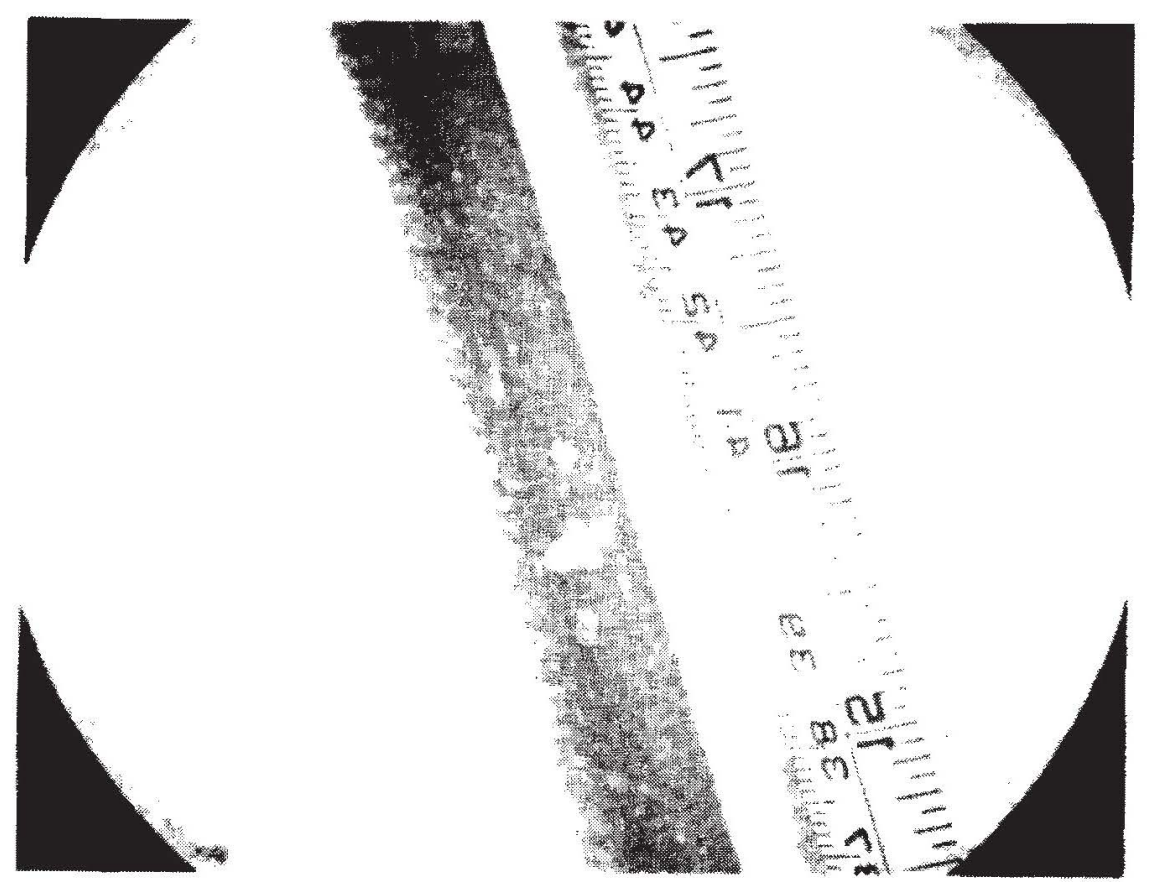

F1g. 24 Posttest photograph of fuel rod from RIA-ST-3 between the 0.360 and $0.450 \mathrm{~m}$ rod elevations

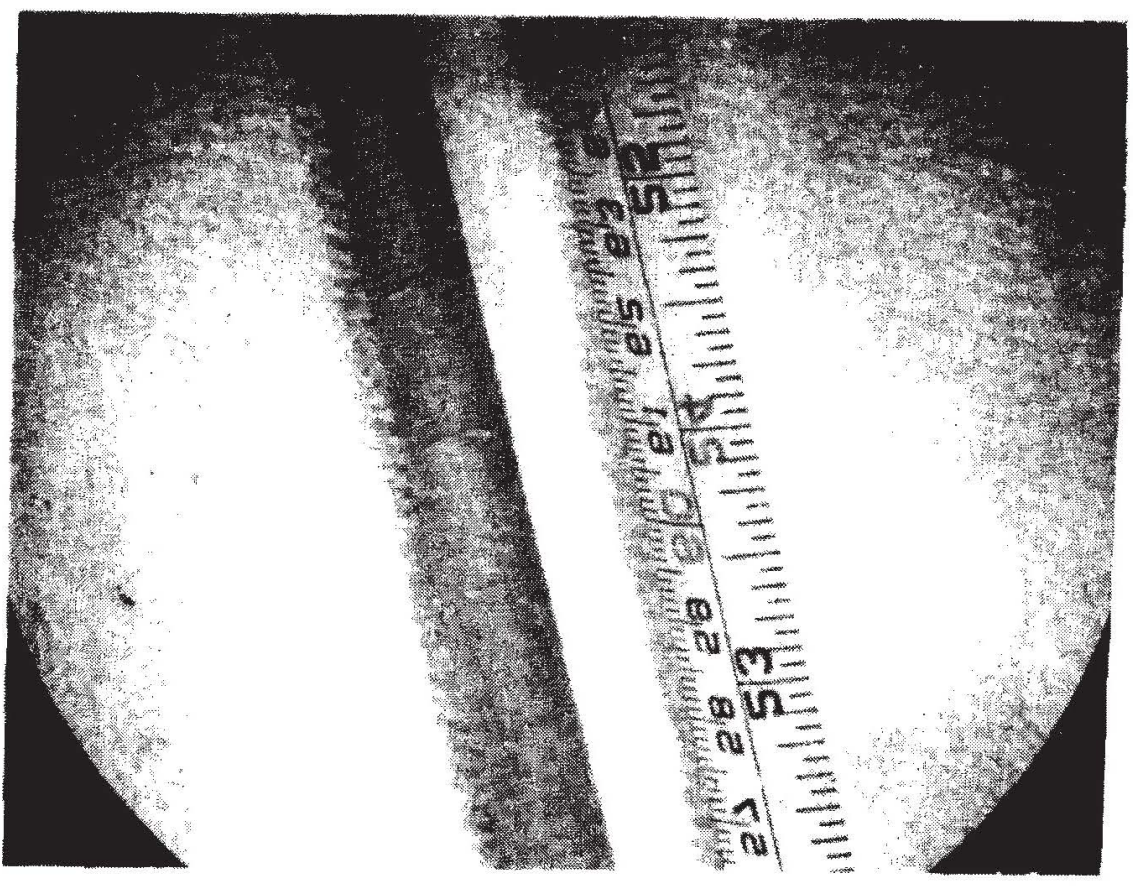

F1g, 25 Posttect photograph of fuel rod from RIA-ST-3 near $0,600 \mathrm{~m}$ rod elevation 


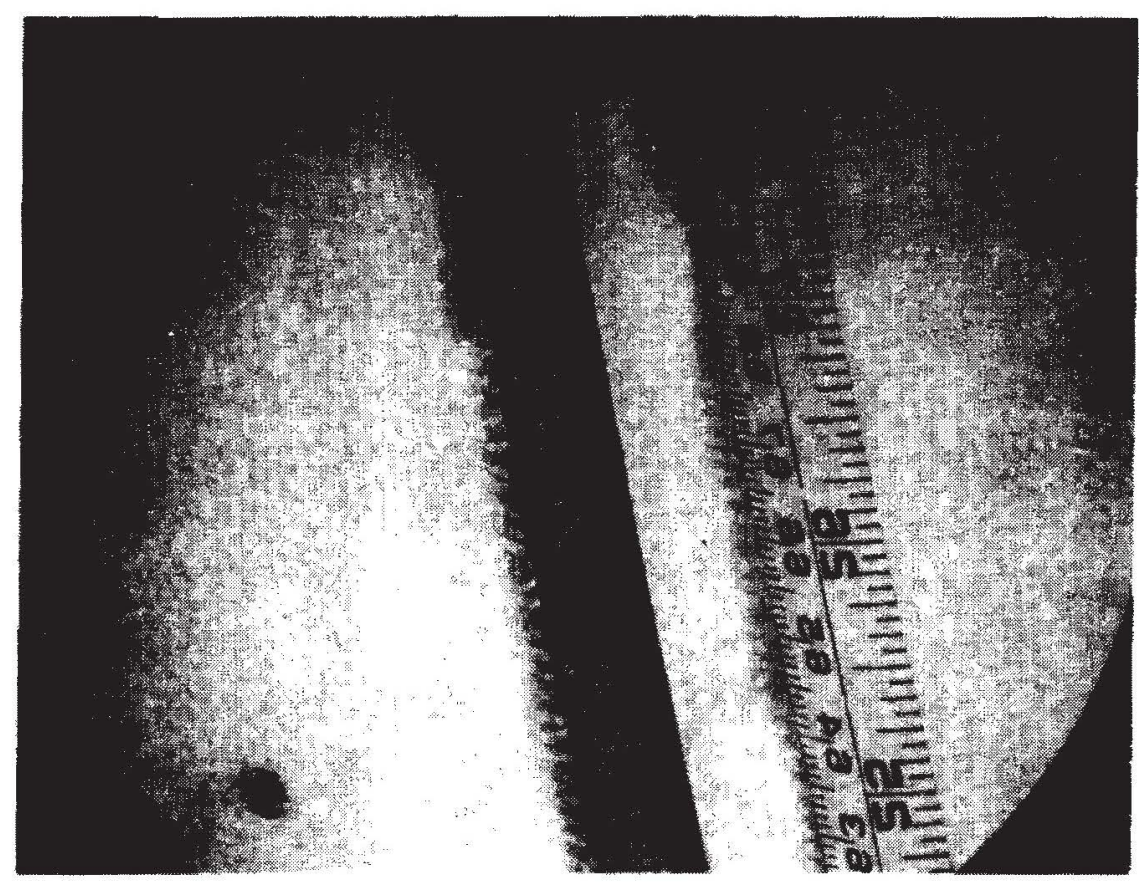

Fig, 26 Posttest photograph of fuel rod from RIA-ST-3 near $0.660 \mathrm{~m}$ rod elevation 


\section{FISSION PRODUCT DETECTOR}

The fission product detection system was operated during all RIA-ST power bursts to establish rod failure. The gross gamma and delayed neutron activity provided a relative indication of the failure extent during the tests; the gamma spectroscopic system data will provide the concentration of individual isotopes released during and following the rod failure.

Following the second power burst of RIA-ST-1, and the power bursts of RIA-ST-2 and RIA-ST-4, rod failure was indicated by an increased gamma count rate as shown in Figures 27,28 , and 30 , respectively. During RIA-ST-3 an increase was not observed indicating failure had not occurred (Figure 29). There was a significant difference in the maximum count rates measured during RIA-ST-1, RIA-ST-2, and RIA-ST-4 indicating that the RIA-ST-4 rod sustained more extensive failure.

The delay time from the burst to the increase in gamma activity at the detector station during RIA-ST-1 and RIA-ST-2 was approximately 7.5 minutes; during RIA-ST-4 the delay time was 23.25 minutes. The difference in delay time is not due to differences in loop flow rates since the loop flow rate was nearly the same for each power burst. 


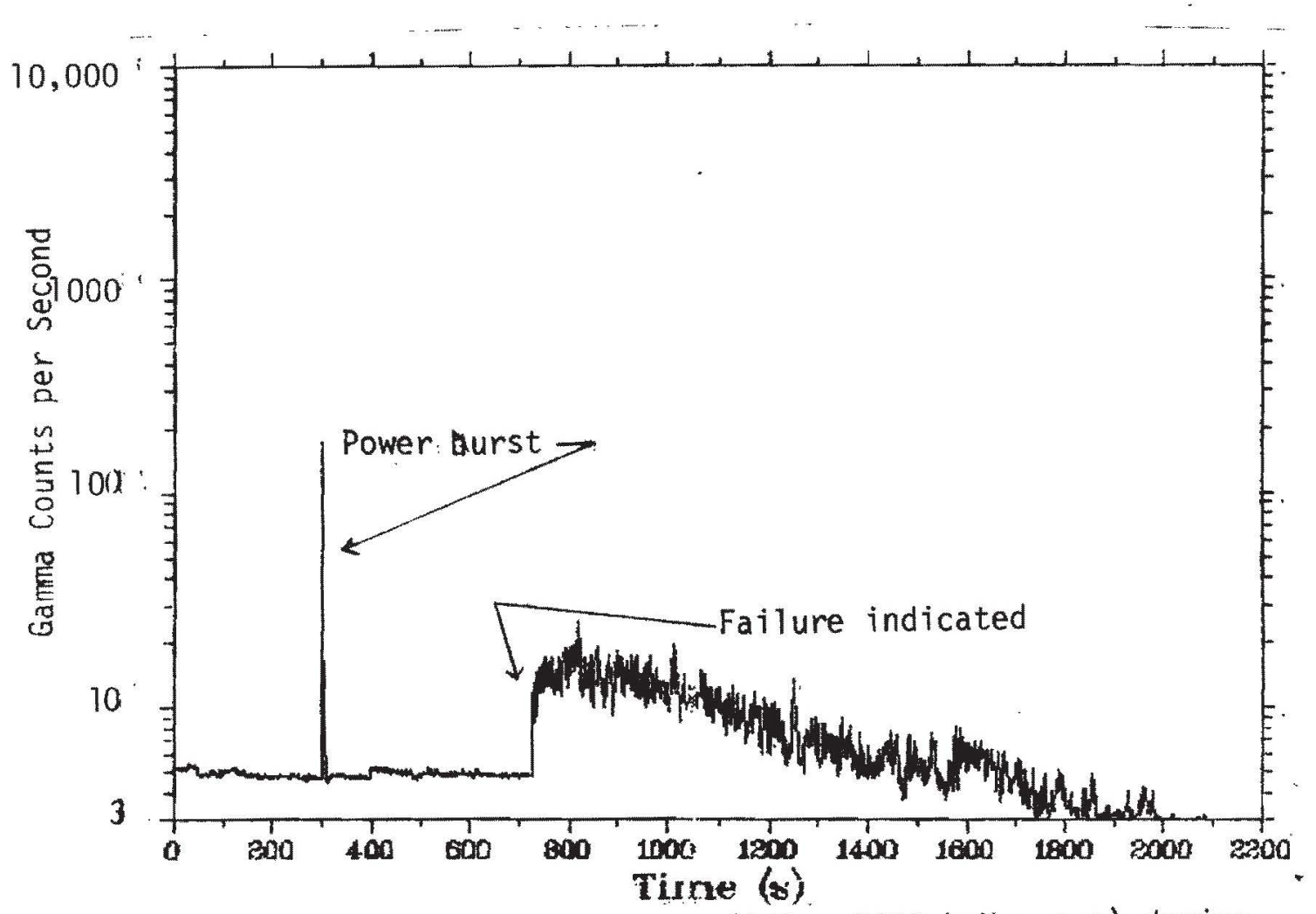

Fig. 27 Gross gamma count rate $(150$ - $3400 \mathrm{keV}$ range) during Scoping Test 1 burst 2 .

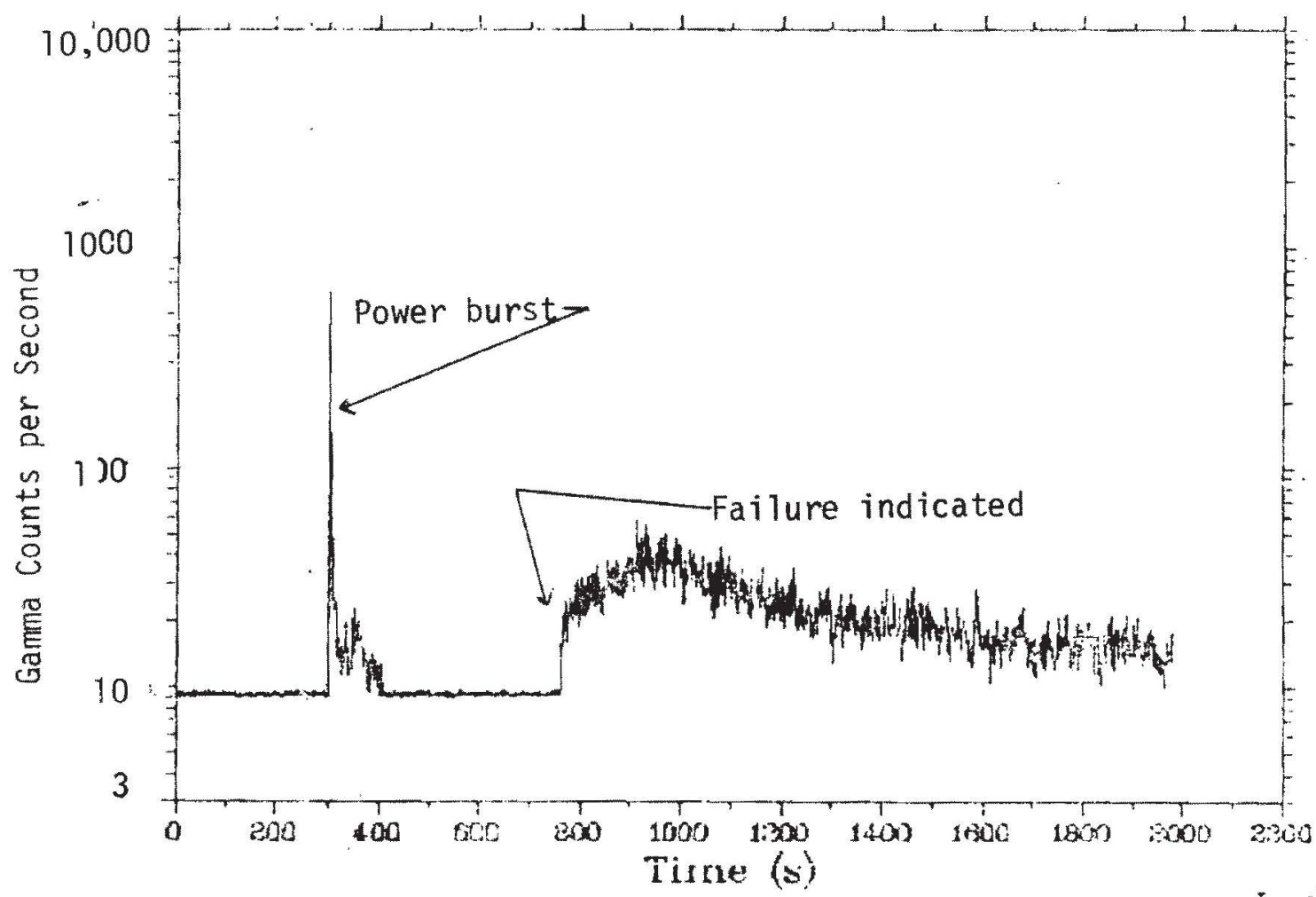

Fig. 28 Gross gamma count rate $(150-3400 \mathrm{keV}$ range) durins Scoping Test 2 . 


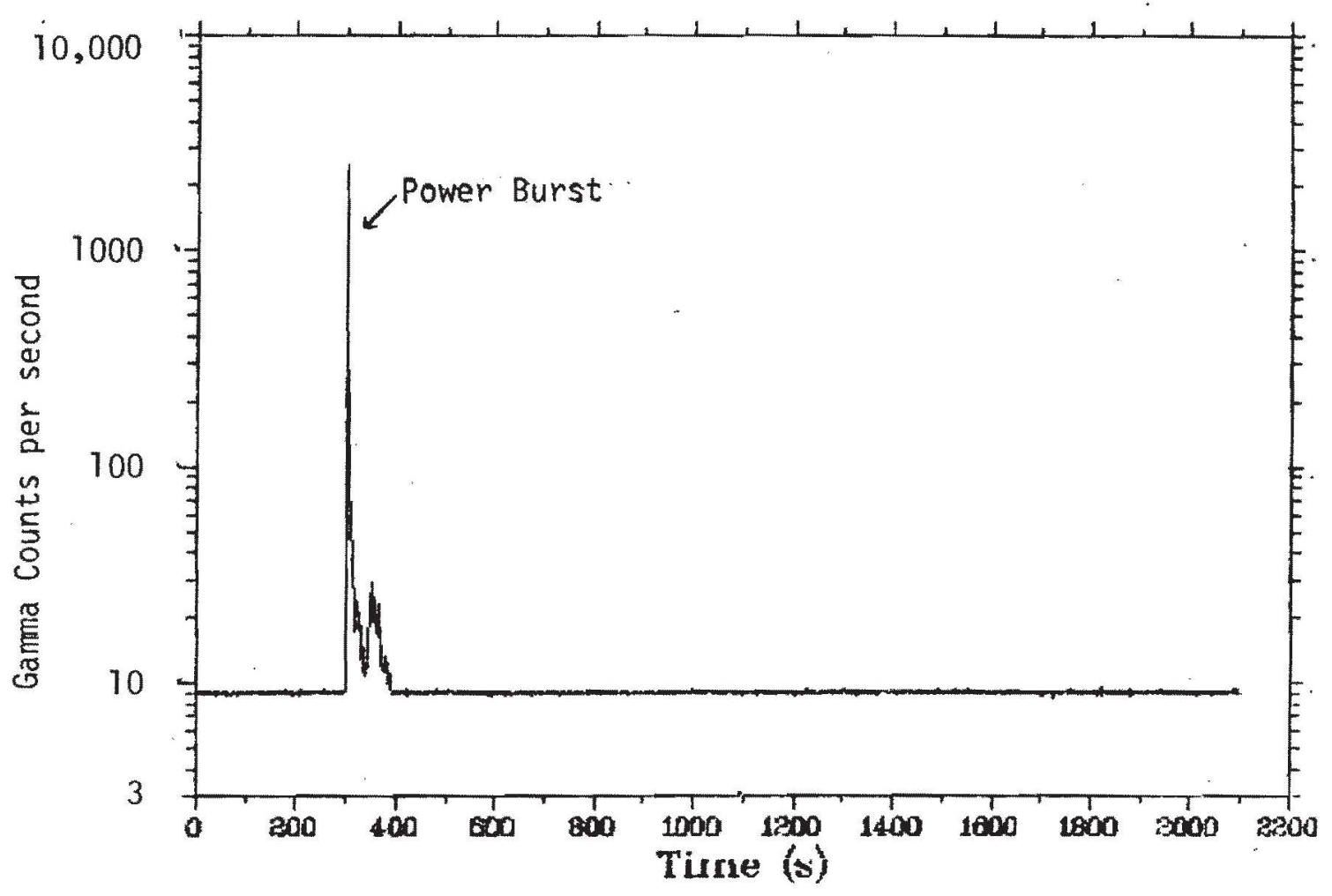

Fig. 29 Gross gamma count rate (150 - $3400 \mathrm{keV}$ range) during Scoping Test 3 . No failure indicated.

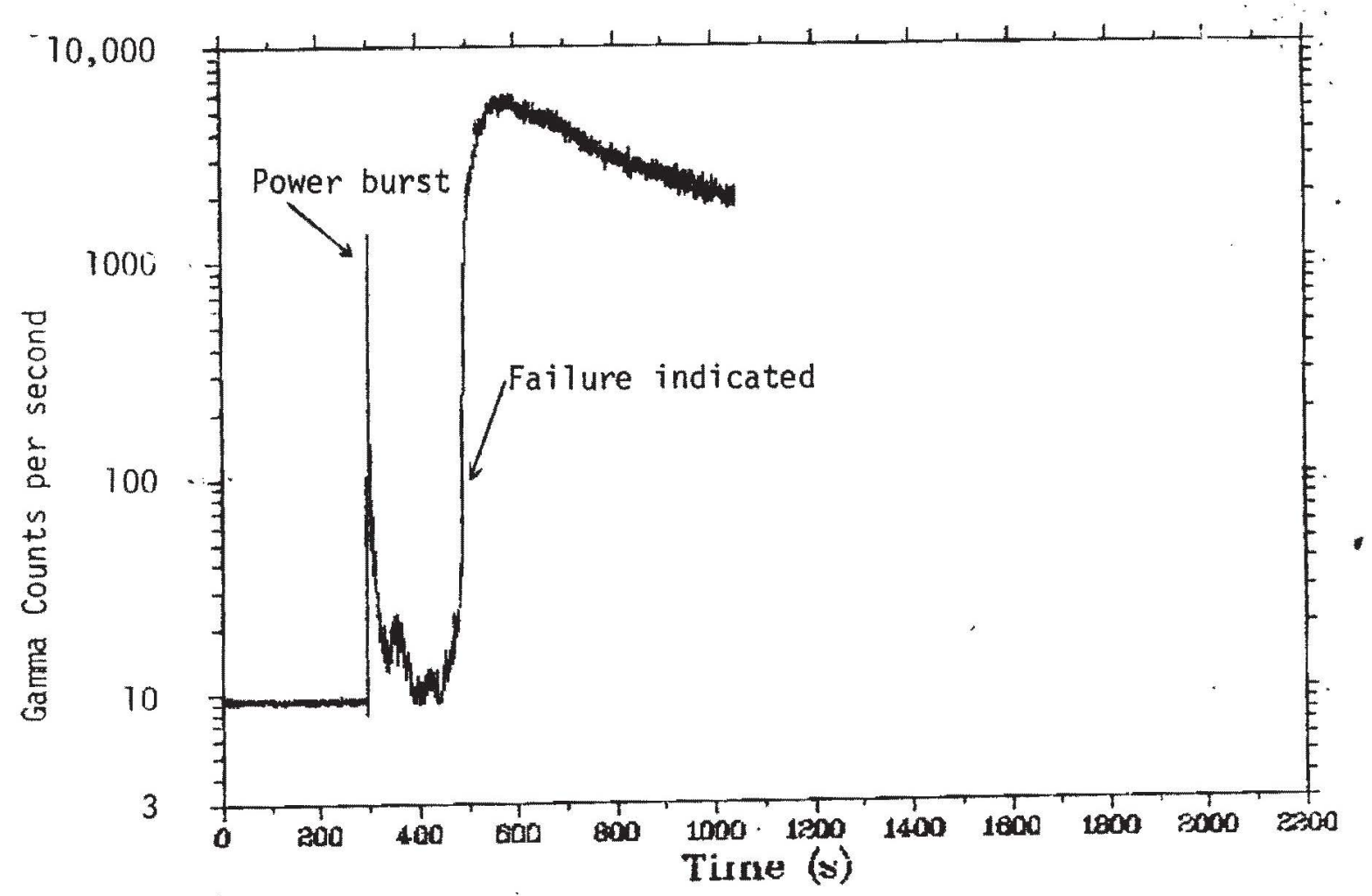

Fig. 30 Gross gamma count rate (150 - $3400 \mathrm{keV}$ range) during Scoping Test 4 power burst. 


\section{CONCLUSIONS}

The RIA Scoping Test has provided data regarding the four main objectives of the test. These results are summarized below.

(1) Definite conclusions regarding the applicability of calorimetric measurements to determine fuel rod energy during a power burst must await radiochemical analysis results. The calculated power calibration ratio of fuel rod power to reactor power was in excellent agreement with reactor physics calculations. Relating the calorimetric power calibration results to the SPNDs yielded fuel rod energy depositions about $25 \%$ higher than those determined from the core power chambers. Current evidence indicates that the SPND values are in error. Further analysis will be required.

(2) The failure threshold of unirradiated fuel rods determined calorimetrically under BWR hot startup conditions is between 218 and $256 \mathrm{cal} / \mathrm{g} \mathrm{UO} \mathrm{O}_{2}$ (pellet surface energy at the axial flux peak). These values are slightly below those of pretest predictions.

(3) Although a large source pressure was measured during RIA-ST-4, only low magnitude pressures were measured elsewhere in the IPT and loop piping.

(4) The most significant problem regarding instrument performance is the turbine flowmeter. Resolution of this problem is required before meaningful coolant flow time history measurements during a power burst can be made for future RIA tests. Another RIA test concern is the short operating lifetime due to bearing seizure of the turbine flowmeters following fuel rod failure. None of the turbine flowmeters would rotate following RIA-ST-1, RIA-ST-2, or RIA-ST-4. 
In addition, new information regarding consequences of fuel rod failure under BWR hot startup conditions has been provided. The RIA Scoping Test has shown that large amounts of $\mathrm{UO}_{2}$ can be expected to be expelled or washed out into the coolant for an RIA event occurring at high temperature, pressure, and forced coolant flow conditions. Only a slight loss of fuel from the cladding occurred during previous tests conducted at CDC and NSRR in a closed capsule at ambient conditions. 


\section{REFERENCES}

1. R. S. Semken, T. Inabe, Z. R. Martinson, Reactivity Initiated Accident Test Series RIA Scoping Test Experiment Operating Specification, TFBP-TR-217 (May 1978).

2. R. S. Semken, A. M. Eaton, R. H. Smith, S. C. Resch, Reactivity Initiated Accident Test Series RIA Scoping Test Experiment Predictions, TFBP-TR-275 (June 1978). 
a

- 
R. G. Ambrosek

R. W. Barber (DOE)

R. L. Benedetti

M. P. Bohn

R. J. Buckland

D. Coleman

J. G. Crocker

B. R. DaBell

J. A. Dearien, Jr.

G. H. Dechman

W. F. Domentco

C. 0. Doucette

R. J. Drake

E. E. Felix

S. R. Gossmann

W. R. George

R. N. Hagen

J. C. Haire

D. E. Hill

A. M. Jensen

W. V. Johnston (NRC)

J. E. Koch

M. M. Larson

B. H. Little (DOE)

W. G. Lussie

Z. R. Martinson (10)

R. W. Marshall, Jr.

R. D. McCormick

F. A. Meichle

E. V. Mobley

M. N. Monson

P. North

S. Resch

L. J. Siefken

J. Sielinsky

D. L. Smith

L. A. Stephan

F. E. Stoll

P. 0. Strom (NRC)

K. G. Therp

R. E. Tiller (DOE) (4)

E. L. Tolman

R. D. UIrich

R. VanHouten (NRC)

C. E. White

L. J. Ybarrondo

M. W. Young

T. E. Young
J. 0. Zane

H. J. Zelle

C. L. Zimmermann

R. L. Doley

$R$, L. Persons

Ait Division Personnel 
$\therefore$

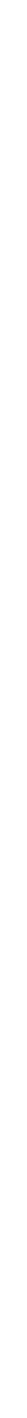

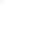

